\title{
ERP Effects of Subject-Verb Agreement Violations in Patients with Broca's Aphasia
}

\author{
Marlies Wassenaar', Colin M. Brown ${ }^{1}$, and Peter Hagoort ${ }^{2}$
}

\begin{abstract}
This article presents electrophysiological data on on-line syntactic processing during auditory sentence comprehension in patients with Broca's aphasia. Event-related brain potentials (ERPs) were recorded from the scalp while subjects listened to sentences that were either syntactically correct or contained violations of subject-verb agreement. Three groups of subjects were tested: Broca patients $(n=10)$, nonaphasic patients with a right-hemisphere $(\mathrm{RH})$ lesion $(n=5)$, and healthy agedmatched controls $(n=12)$. The healthy, control subjects showed a P600/SPS effect as response to the agreement violations. The nonaphasic patients with an $\mathrm{RH}$ lesion showed essentially the same pattern. The overall group of Broca patients did not show this sensitivity. However, the sensitivity
\end{abstract}

\section{INTRODUCTION}

Disorders of syntax resulting from brain damage have most often been studied in patients with Broca's aphasia. To explain syntactic comprehension problems in these patients, several accounts have been given (see, for a review, Kolk, 1998). In accounts that view the syntactic impairment as a processing deficiency, emphasis has been put either on limitations in processing capacity (e.g., Haarmann, Just, \& Carpenter, 1997; Miyake, Carpenter, \& Just, 1994, 1995) or on changes in the temporal organization of the parsing process (Hagoort, 1990): It has been suggested that the activation of grammatical information is slowed down (e.g., Haarmann \& Kolk, 1991a, 1991b; Friederici, 1988; Friederici \& Kilborn, 1989) or that syntactic information is subjected to a pathologically fast decay (e.g., Haarmann \& Kolk, 1994). These studies on slow activation or fast decay have in common that syntactic processing was studied on-line, that is, with the help of tasks (viz., lexical decision and word monitoring) that tap the syntactic comprehension process as it unfolds in real time. However, these tasks require subjects to make fast and accurate responses. For instance, in a lexical decision task, subjects are asked to decide as fast and accurately as possible whether a presented string of letters or sequence of sounds is a

\footnotetext{
${ }^{1}$ Max Planck Institute for Psycholinguistics, ${ }^{2} \mathrm{~F}$. C. Donders Centre for Cognitive Neuroimaging, The Netherlands
}

was modulated by the severity of the syntactic comprehension impairment. The largest deviation from the standard P600/SPS effect was found in the patients with the relatively more severe syntactic comprehension impairment. In addition, ERPs to tones in a classical tone oddball paradigm were also recorded. Similar to the normal control subjects and RH patients, the group of Broca patients showed a P300 effect in the tone oddball condition. This indicates that aphasia in itself does not lead to a general reduction in all cognitive ERP effects. It was concluded that deviations from the standard P600/SPS effect in the Broca patients reflected difficulties with on-line maintaining of number information across clausal boundaries for establishing subject-verb agreement.

word or not. In testing aphasic patients, such tasks have the following disadvantages: (i) Patients with severe comprehension deficits might not understand the task. (ii) Performing the task might interfere with the real-time language processing operations under study. An on-line method that can be applied without any additional task, over and above the natural one of listening to speech, is the event-related brain potential (ERP) method.

ERPs are small voltage changes in the EEG, recorded at the scalp and time-locked to the onset of a particular event (e.g., the onset of words in sentences). In relation to the processing of syntax, two ERP effects are especially relevant: the LAN and the P600/SPS (see, for a review, Hagoort, Brown, \& Osterhout, 1999). In a number of studies, negative-going ERP effects have been reported that seem to be related to syntactic processing. These effects differ from the N400 effect (Kutas \& Hillyard, 1980) in that they have a more anterior distribution. These socalled left anterior negativity (LAN) effects occur with a latency between 300 and 500 msec poststimulus onset (Friederici, Hahne, \& Mecklinger, 1996; Kluender \& Kutas, 1993; Münte, Heinze, \& Mangun, 1993; Rösler, Friederici, Pütz, \& Hahne, 1993) or, sometimes, in an earlier latency range between 125 and $180 \mathrm{msec}$ (Friederici, Pfeifer, \& Hahne, 1993; Neville, Nicol, Barss, Forster, \& Garrett, 1991). LAN effects have been elicited by violations of word-category constraints (i.e., when a word of a certain syntactic class is replaced by a word of a different syntactic class) (e.g., Friederici et al., 1996; Münte et al., 
1993; Rösler et al., 1993), but also by violations of number, gender, and tense agreement (e.g., Münte et al., 1993; Münte \& Heinze, 1994). The distribution of these effects is usually more bilateral than left lateralized. A more strictly left-lateralized LAN effect has been related to verbal working memory (Coulson, King, \& Kutas, 1998b; Kluender \& Kutas, 1993).

Another ERP effect that has been related to syntactic processing is the P600/SPS. The P600/SPS effect is characterized by a positive deflection, starting at about $500 \mathrm{msec}$ poststimulus onset and elicited by a word that creates a syntactic processing problem. This effect has been observed in response to a variety of syntactic violations (e.g., of phrase structure, verb subcategorization, number, and gender agreement) (e.g., AinsworthDarnell, Shulman, \& Boland, 1998; Coulson et al., 1998b; Münte, Matzke, \& Johannes, 1997; Friederici et al., 1996; Hagoort, Brown, \& Groothusen, 1993; Osterhout \& Holcomb, 1992; Osterhout, Holcomb, \& Swinney, 1994; Osterhout \& Mobley, 1995; Neville et al., 1991). However, an outright syntactic violation is not required to elicit a P600/SPS effect. The effect has also been observed in sentences when a preferred syntactic analysis can no longer be maintained (e.g., Van Berkum, Brown, \& Hagoort, 1999; Osterhout et al., 1994) or when syntactic complexity is increased (Kaan, Harris, Gibson, \& Holcomb, 2000).

The purpose of this present study is to investigate agrammatic comprehension in patients with Broca's aphasia by exploiting the sensitivity of the P600/SPS effect to syntactic processing. One of the antecedent conditions of a P600/SPS effect is a violation of a syntactic constraint. In this study, violations of subject-verb agreement are used. Haarmann and Kolk (1994) found in a word monitoring study that patients with Broca's aphasia were sensitive to subject-verb agreement violations when these violations were couched in conjoined sentences (e.g., "*The baker greets the customers and ask the boy to not make so much noise"). The effect was, however, not obtained with embedded sentences (e.g., "*The baker that greets the customers ask the boy to not make so much noise"), unlike normal control subjects who showed this effect for both conditions. Following Haarmann and Kolk, for our present study the on-line sensitivity to subject-verb agreement violations is tested for both conjoined and embedded sentences. Conjoined and embedded sentences differ in phrase structure complexity (see Materials section).

For the neurologically unimpaired subjects, we expect, based on earlier experiments with Dutch agreement violations (Hagoort \& Brown, 2000), a P600/SPS effect in response to the agreement violations. Deviant patterns of ERP effects in Broca patients can reflect changes in their syntactic processing (Friederici, 2001): If comprehension deficits in aphasia affect the rate at which syntactic information is processed, a delay of the
P600/SPS effect might be expected. If the efficiency of syntactic processing is suboptimal, an amplitude reduction of the P600/SPS effect could result. In addition, the severity of the syntactic comprehension deficit is of interest: The largest deviation from the normal P600/SPS effect is expected for those patients with the most severe comprehension deficits.

The results of the patients with Broca's aphasia will be compared to a group of normal, age-matched controls and to a group of nonaphasic patients with a lesion in the right hemisphere, to control for nonspecific effects of aging and brain damage on the P600/SPS effect. To check whether possible changes in the P600/SPS effect in the aphasic patients could be dissociated from general effects of brain damage on cognitive ERP components, we included a nonlinguistic control experiment: Subjects were also tested with a classical tone oddball paradigm. Normally, this paradigm elicits a P300. Comparing the pattern of $\mathrm{P} 300$ results to the $\mathrm{P} 600 / \mathrm{SPS}$ results of the language task will help to determine whether changes in the P600/SPS effect are related to altered syntactic processing rather than to an aspecific consequence of brain damage.

In the next section we will first present behavioral data (scores on a syntactic comprehension test), then the ERP data for listening to the conjoined (e.g., The women pay the baker and take/takes the bread home) and the embedded sentences (e.g., The women who pay the baker, take/takes the bread home), and, finally, the ERP data from the tone oddball paradigm.

\section{RESULTS}

\section{Off-line Test for Syntactic Comprehension}

Figure 1 shows the comprehension scores (in percentage correct) on the off-line test for syntactic sentence comprehension (see Methods section) of the normal control subjects, the RH patients, and the patients with Broca's aphasia. Analyses were performed on the percentage correct scores for the five sentence types of the syntactic off-line test. The data were entered into repeated measures analyses of variance (ANOVAs) with group (normal controls, RH patients, and Broca patients) as a betweensubjects factor and sentence type (I-V) as a within-subjects factor. A Huynh-Feldt correction was applied when necessary, and Kramer's modification of Tukey's HSD test $(\alpha=.05)$ was used for post hoc analysis. The adjusted degrees of freedom and $p$ values are reported. Analyses with group as factor revealed that syntactic complexity had a differential effect on the comprehension scores of the different subject groups: sentence type: $F(3.38$, $81.12)=27.02, S E M=110.70, p=.000$; group: $F(2,24)$ $=21.29, S E M=937.73, p=.000$; sentence type $\times$ group: $F(6.76,81.12)=6.92$, SEM $=110.70, p=.000$. Post hoc analyses $(\alpha=.05)$ revealed that the Broca patients performed significantly worse than the normal controls 


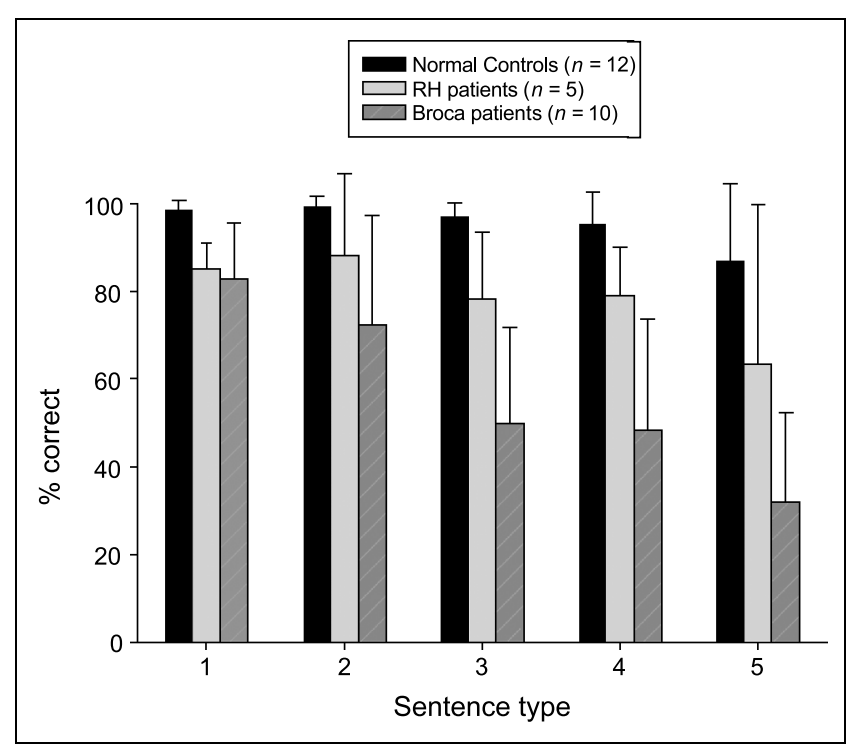

Figure 1. Scores of the group of normal controls $(n=12)$, the RH control patients $(n=5)$, and the group of Broca patients $(n=10)$ for the off-line test for syntactic comprehension; for the five types of syntactic complexity: I = active, semantically irreversible; II = active, semantically reversible; III = simple passive; $\mathrm{IV}=$ sentences with active relative clause; $\mathrm{V}=$ sentences with passive relative clause.

on all sentence types except Type I and significantly worse than the RH patients on sentence types III-V. In contrast, the normal controls and the RH patients did not differ significantly from each other, except on sentence type V. The size of the difference in comprehension scores between the Broca patients and the two control groups increased with increasing syntactic complexity. For the most complex sentence type the performance of the Broca patients approached chance level (25\% on this test). This pattern of results substantiates the syntactic comprehension problems of the Broca patients in this study.

\section{ERP Experiment}

The ERP data for the 12 normal control subjects, the 5 RH patients, and the 10 Broca patients are presented in separate sections. In addition, the ERP results for the nonlinguistic control experiment (viz., tone oddball task) will be described. Prior to off-line averaging, all single-trial waveforms were screened for electrode drifting, amplifier blocking, muscle artefacts, eye movements, and blinks in a critical window that ranged from $600 \mathrm{msec}$ before to $1500 \mathrm{msec}$ after onset of the critical word (CW). The CW in this experiment is the incorrectly inflected verb form and its correct counterpart. Trials containing artefacts were rejected. However, for subjects with a substantial number of blinks, single trials were corrected via a procedure described by Gratton, Coles, and Donchin (1983). After artefact rejection, the overall rejection rate was $21.7 \%$ for the normal elderly control subjects, $25.2 \%$ for the $\mathrm{RH}$ patients, and $21.8 \%$ for the patients with Broca's aphasia. For all groups, rejected trials were evenly distributed among conditions. For each subject, average waveforms were computed across all remaining trials per condition after normalizing the waveforms of the individual trials on the basis of a 150-msec pre-CW baseline. Mean amplitude values for each subject were computed in the following latency windows: 400-600 msec, and 600-1200 msec after onset of $\mathrm{CW}$. These latency ranges were determined on the basis of a visual inspection of the waveforms and on the basis of earlier studies. The mean amplitude values were entered into repeated measures ANOVAs for each subject group, respectively with complexity (two levels: conjoined, embedded), agreement (two levels: correct, incorrect) and electrode site (13 levels) as within-subjects factors. The Huynh-Feldt correction was applied when necessary. The adjusted degrees of freedom and $p$ values will be presented. The results of the ANOVAs are listed in Tables 1 to 9. To test for differences between the results for the normal controls and the patient groups, also group analyses are performed in the specified time windows, with group of subjects as the additional between-subjects factor.

\section{Normal Control Subjects}

Figure 2 displays the grand average waveforms elicited by the $\mathrm{CW}$ in the subject-verb agreement conjoined condition for the normal elderly control subjects. The incorrect critical words elicit a clear positive deflection in comparison to the correct words. This positive shift starts at around $500 \mathrm{msec}$ after the acoustic onset of the word that renders the sentence ungrammatical. This grammaticality effect is strongest over posterior sites and has the characteristic morphology, time course and distribution of a P600/SPS effect (Hagoort et al., 1999; Osterhout \& Holcomb, 1992, 1993). In addition, an early negativity (400-600 msec) was visible that preceded the P600/SPS effect in latency and this negativity was most prominent at the F8 and FT8 site.

Figure 3 shows the grand average waveforms elicited by the $\mathrm{CW}$ in the embedded condition. The incorrect critical words elicit a clear positive deflection in comparison to the correct words, with the same characteristics as for the agreement violation in the conjoined condition. In addition, the frontal left and right electrode site showed a sustained negative deflection for the violation condition.

An ANOVA with all electrode sites (see Table 1) showed that the violation of subject-verb agreement had a significant main effect on mean amplitude in the 600- to 1200-msec latency window, with an effect size of 1.43 and $1.15 \mu \mathrm{V}$ for the conjoined and embedded condition, respectively. In the 600- to 1200-msec window, neither the complexity effect nor the complexity by agreement interaction became significant in the 
Figure 2. Grand average ERP waveforms for the group of normal control subjects $(n=12)$ elicited by critical correct words (solid line) or incorrect words (dotted line) in the subject-verb agreement (conjoined) condition. In this and all following figures, negativity is plotted up wards. The onset of the CW is at $0 \mathrm{msec}$.

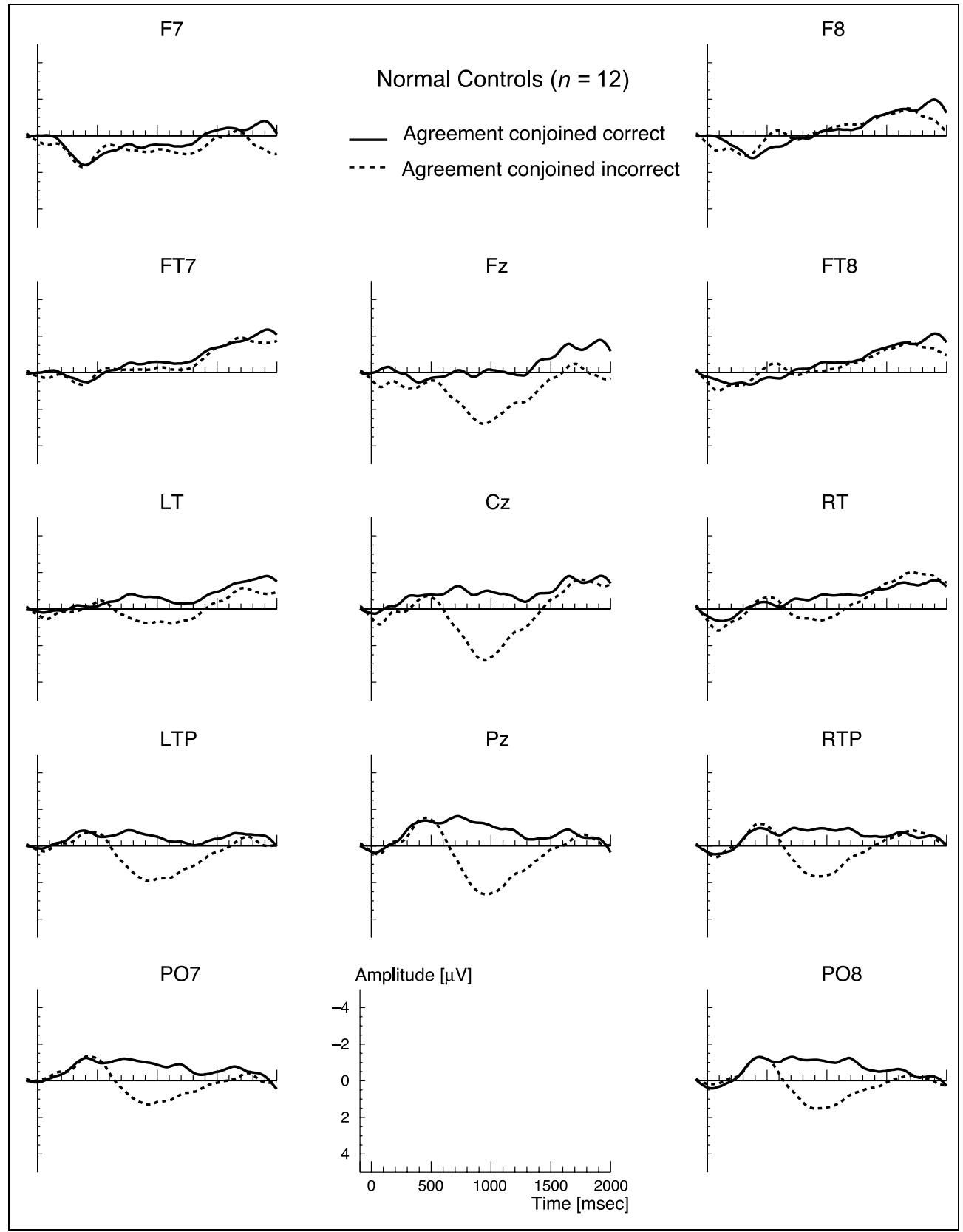

omnibus ANOVA, showing that these control subjects showed sensitivity to subject-verb agreement violations irrespective of whether the sentences were conjoined or embedded. The agreement effect interacted significantly with electrode site, due to its posterior distribution. The agreement effect was largely symmetrical as indicated by the absence of an agreement by hemisphere interaction.

The negative effect that preceded the P600/SPS effect was mainly visible for the anterior sites and was tested in the 400-600 msec window (see Table 2). The analysis for anterior electrodes (F7, F8, FT7, FT8) failed to show a significant effect of agreement. In addition, interactions with complexity failed to reach significance.
In sum, the normal elderly controls showed the expected P600/SPS effect to the violations of subjectverb agreement. They were sensitive to these violations irrespective of phrase structure complexity.

\section{RH Patients}

Figures 4 and 5 present the grand average waveforms for the $\mathrm{RH}$ patients. In the conjoined condition, the incorrect critical words elicited a positive deflection in comparison to the correct words mainly over centroposterior electrode sites. This positive shift started at around $600 \mathrm{msec}$ following the onset of the critical word and has the 
Figure 3. Grand average ERP waveforms for the group of normal control subjects $(n=12)$ elicited by critical correct words (solid line) or incorrect words (dotted line) in the subject-verb agreement (embedded) condition. The onset of the $\mathrm{CW}$ is at $0 \mathrm{msec}$.

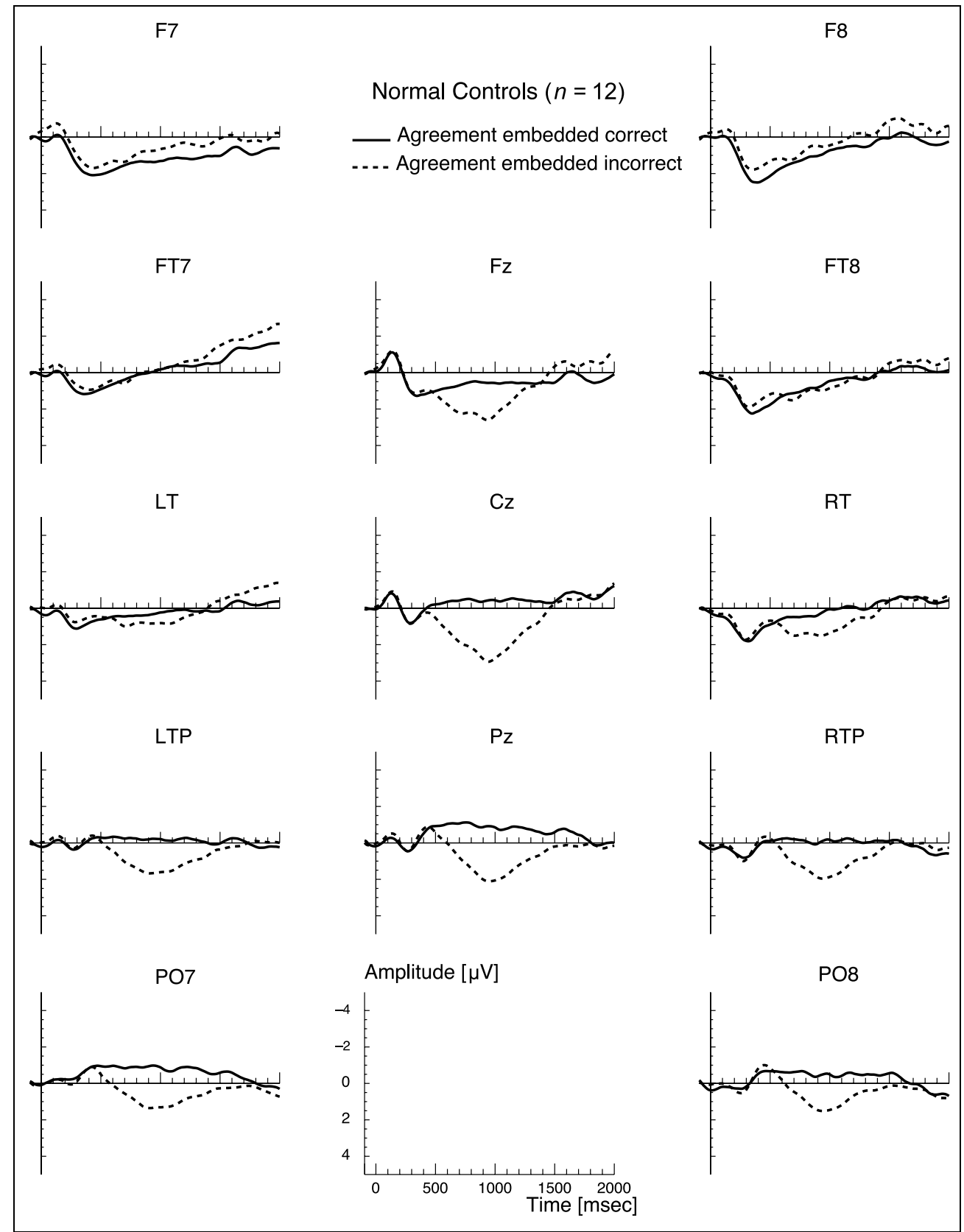

characteristics of a P600/SPS effect. In addition, the P600/ SPS effect was preceded by a negative effect (latency range: $400-800 \mathrm{msec}$ ), which is mainly present at anterior and centrotemporal electrode sites.

The agreement violation in the embedded condition elicited an effect that is strongest over posterior sites and is characterized by a positive shift. For the posterior electrode sites, this P600/SPS effect started at around $600 \mathrm{msec}$ following the onset of the critical word.

An ANOVA with all electrode sites (see Table 3) showed that the violation of subject-verb agreement had a marginally significant effect in the 600- to 1200-msec latencywindow, with an effect size of 0.50 and $0.58 \mu \mathrm{V}$ for the conjoined and embedded condition, respectively. The agreement by electrode interaction was significant due to the posterior topography of the effect. We therefore performed an additional ANOVA in which only the posterior sites (Pz, LTP, RTP, PO7, PO8) were included. This analysis for the 600- to 1200-msec window resulted in a significant effect of agreement. Neither the complexity effect nor the complexity by agreement interaction became significant for the posterior sites.

The negative effect that preceded the P600/SPS effect in the conjoined sentences was tested in the 400 - to $600-\mathrm{msec}$ window (see Table 4). The analysis for anterior electrodes (F7, F8, FT7, FT8) did not yield a significant effect of agreement, and the interaction between complexity and agreement was only marginally significant. 
Table 1. Subject-Verb Agreement Violations for Normal Control Subjects: Mean ERP Amplitude ANOVAs in the 600- to 1200-msec Latency Range following the Onset of the Critical Word

\begin{tabular}{lcrrr}
\hline Source & $d f$ & $F$ & SEM & $p$ \\
\hline Omnibus ANOVA (13 electrodes) & & & \\
Complexity & 1,11 & 3.04 & 11.61 & .109 \\
Agreement & 1,11 & 21.17 & 11.65 & $.001^{* * *}$ \\
Compl $\times$ Agree & 1,11 & 2.14 & 2.14 & .171 \\
Compl $\times$ El & $4.09,44.94$ & 1.98 & 0.68 & .113 \\
Agree $\times$ El & $4.19,46.13$ & 17.25 & 0.75 & $.000^{* * *}$ \\
Compl $\times$ Agree $\times$ El & $5.80,63.80$ & 0.80 & 0.33 & .568
\end{tabular}

Midline ANOVA (3 electrodes)

$\begin{array}{llrll}\text { Complexity } & 1,11 & 0.36 & 6.98 & .559 \\ \text { Agreement } & 1,11 & 37.24 & 5.66 & .000^{* * * *} \\ \text { Compl } \times \text { Agree } & 1,11 & 1.71 & 0.95 & .218 \\ \text { Compl } \times \mathrm{El} & 1.60,17.60 & 1.55 & 0.40 & .239 \\ \text { Agree } \times \mathrm{El} & 1.34,14.71 & 6.71 & 0.50 & .015^{*} \\ \text { Compl } \times \text { Agree } \times \mathrm{El} & 2,22 & 0.55 & 0.43 & .586\end{array}$

Posterior ANOVA (5 electrodes)

$\begin{array}{llrll}\text { Complexity } & 1,11 & 0.38 & 7.41 & .548 \\ \text { Agreement } & 1,11 & 27.26 & 8.94 & .000 * * * \\ \text { Compl } \times \text { Agree } & 1,11 & 1.91 & 1.43 & .195 \\ \text { Compl } \times \mathrm{El} & 3.46,38.01 & 1.25 & 0.39 & .306 \\ \text { Agree } \times \mathrm{El} & 2.79,30.73 & 4.54 & 0.40 & .011 * \\ \text { Compl } \times \text { Agree } \times \mathrm{El} & 2.97,32.71 & 0.78 & 0.26 & .513\end{array}$

Lateral ANOVA $(2 \times 5$ electrodes $)$

\begin{tabular}{|c|c|c|c|c|}
\hline Complexity & 1,11 & 5.21 & 6.67 & $.043^{*}$ \\
\hline Agreement & 1,11 & 13.28 & 7.46 & $.004 * *$ \\
\hline Compl $\times$ Agree & 1,11 & 1.90 & 1.59 & .195 \\
\hline Compl $\times \mathrm{El}$ & $1.61,17.73$ & 1.79 & 0.85 & .199 \\
\hline Agree $\times$ El & $1.52,16.67$ & 22.06 & 0.97 & $.000 * * *$ \\
\hline Compl $\times$ Hemi & 1,11 & 4.17 & 1.34 & .066 \\
\hline Agree $\times$ Hemi & 1,11 & 0.04 & 1.33 & .853 \\
\hline Compl $\times$ Agree $\times$ Hemi & 1,11 & 0.57 & 0.54 & .465 \\
\hline
\end{tabular}

An omnibus ANOVA (see Table 6) in the 600- to $1200 \mathrm{msec}$ latency range with group of subjects (normal controls, RH patients) as between-subjects factor revealed neither a main effect of group of subjects nor significant interactions. For the 400- to 600-msec latency range (see Table 6), an ANOVA for anterior electrodes showed a significant group of subjects by complexity interaction, and a significant three-way interaction between group of subjects, complexity, and agreement. This was mainly due to the differential effects in the early latency window for the two sentence types in the $\mathrm{RH}$ patients. In sum, the RH patients showed a P600/SPS, which was statistically indistinguishable from that of the normal controls

\section{Broca Patients}

Figure 6 shows the grand average waveforms elicited by the $\mathrm{CW}$ in the conjoined condition for the 10 patients with Broca's aphasia. Unlike the normal elderly controls and the RH patients, a clear positive deflection for the incorrect critical words was absent. Only the midline sites $\mathrm{Cz}$ and $\mathrm{Pz}$ showed a small positive shift starting at around 600 msec. Between 200 and 500 msec, a negative deflection was present for almost all electrode sites, with a slight right-hemisphere preponderance.

Figure 7 displays the grand average waveforms for the embedded condition. For the posterior electrode sites, the waveforms are characterized by a (small) positive shift, starting at around $750 \mathrm{msec}$. In addition, anterior right electrode sites (F8, FT8) showed a broad negative deflection for the violation condition.

Table 2. Subject-Verb Agreement Violations for Normal Control Subjects: Mean ERP Amplitude ANOVAs in the 400- to 600-msec Latency Range following the Onset of the Critical Word

\begin{tabular}{lcccc}
\hline Source & $d f$ & $F$ & SEM & $p$ \\
\hline Anterior ANOVA $(2 \times 2$ electrodes $)$ & & & \\
Complexity & 1,11 & 10.24 & 5.07 & $.008^{* *}$ \\
Agreement & 1,11 & 3.38 & 2.82 & .093 \\
Compl $\times$ Agree & 1,11 & 0.03 & 1.38 & .861 \\
Compl $\times$ El & 1,11 & 0.27 & 0.22 & .612 \\
Agree $\times$ El & 1,11 & 0.78 & 0.39 & .396 \\
Compl $\times$ Hemi & 1,11 & 14.53 & 0.42 & $.003 * *$ \\
Agree $\times$ Hemi & 1,11 & 0.71 & 2.39 & .417 \\
Compl $\times$ Agree $\times$ Hemi & 1,11 & 0.11 & 0.49 & .748 \\
\hline
\end{tabular}

Compl $=$ complexity $($ conjoined vs. embedded); Agree $=$ subject-verb agreement (correct vs. incorrect); $\mathrm{El}=$ electrode; $\mathrm{Hemi}=$ hemisphere $* * p<0.01$. 
Figure 4. Grand average ERP waveforms for the group of $\mathrm{RH}$ patients $(n=5)$ elicited by critical correct words (solid line) or incorrect words (dotted line) in the subject-verb agreement (conjoined) condition. The onset of the CW is at $0 \mathrm{msec}$.

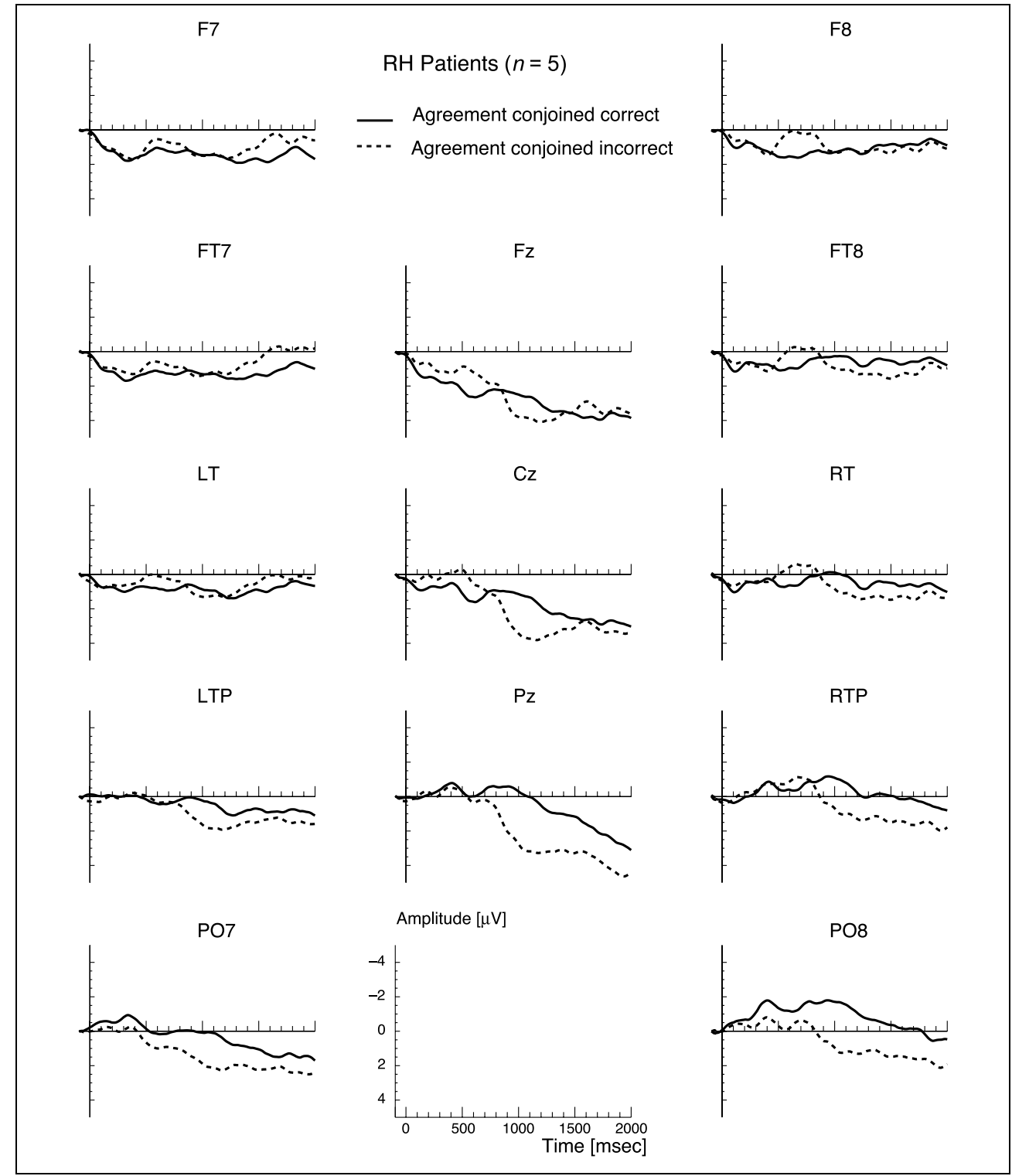

An ANOVA with all electrode sites (see Table 5) did not reveal a significant effect of agreement in the 600- to 1200-msec latency window. When only the posterior electrodes were included, the ANOVA also failed to show a significant agreement effect. No significant interactions were obtained.

The negative-going effect was tested for each agreement condition separately. For the conjoined condition, the negative effect was tested in the 300- to 500-msec latency range. Neither the overall ANOVA nor any site analysis yielded any significant effect of agreement. The negative effect in the embedded condition was primarily visible over F8 and FT8 and was tested in the 600- to 1200-msec latency range. The ANOVA for these right anterior sites revealed a significant agreement effect, $F(1,9)=5.99 ;$ SEM $=0.83 ; p=.037$.

An omnibus ANOVA (see Table 6) in the 600- to 1200 -msec latency range with group of subjects (nor- mal controls, Broca patients) as additional betweensubjects factor showed a significant main effect of group of subjects, but more importantly also a significant group of subjects by agreement interaction.

In sum, whereas the normal controls showed a P600/SPS for both types of sentences (conjoined vs. embedded), the Broca's aphasics did not show this effect for either of these.

It is not inconceivable, however, that the absence of P600/SPS effects in the group of Broca patients is partly due to individual patient variability. It was therefore decided to group these Broca patients in a way that was related to the severity of their individual syntactic comprehension impairment. On the basis of their performance on the syntactic off-line test (see Methods section), the 10 Broca patients were divided into two subgroups. Five Broca patients (subject numbers 1-5 from Table 11) showed an above-chance level of perfor- 
Figure 5. Grand average ERP waveforms for the group of $\mathrm{RH}$ patients $(n=5)$ elicited by critical correct words (solid line) or incorrect words (dotted line) in the subject-verb agreement (embedded) condition. The onset of the $\mathrm{CW}$ is at $0 \mathrm{msec}$

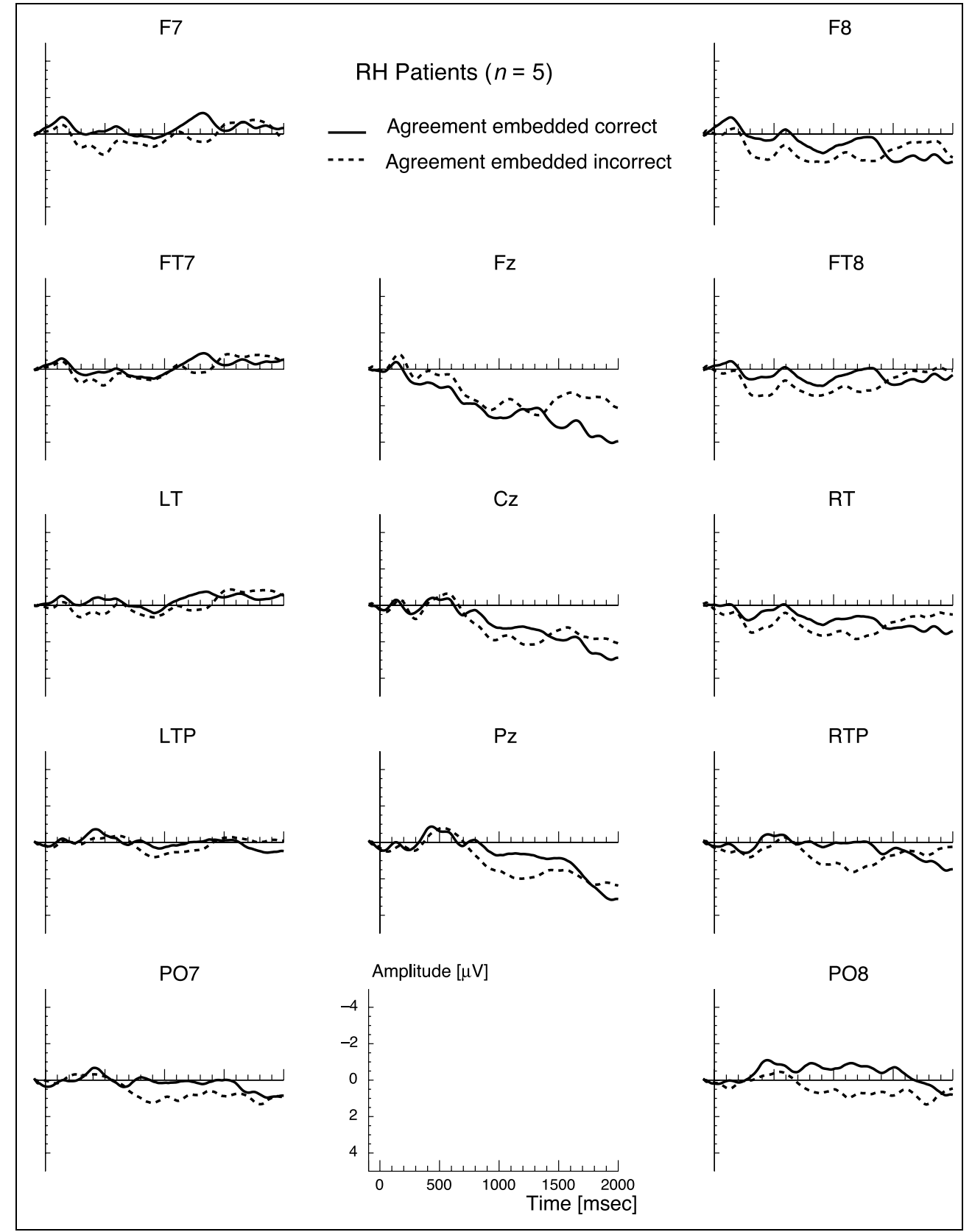

mance, even for the most complex sentence structures. These subjects were classified as "high comprehenders." The other five Broca patients (subject numbers 6-10 from Table 11) showed a level of performance that was just above chance or not different from chance (25\% on this off-line test) for sentence structures that were more complex than simple passive sentences. These subjects were classified as "low comprehenders." An ANOVA (see Table 6) in the 600- to 1200-msec latency range on the mean amplitudes of the 10 Broca patients with group of patients (high comprehenders, low comprehenders) as additional between-subjects factor, yielded a significant group of patients by agreement interaction for the midline electrode sites (high comprehenders: conjoined: $1.70 \mu \mathrm{V}$; embedded: $1.02 \mu \mathrm{V}$; low comprehenders: conjoined: $-0.66 \mu \mathrm{V}$; embedded: $-.09 \mu \mathrm{V}$ ). Because of this group by agreement interaction, ANOVAs were done on the data of the two groups of Broca patients separately.

An ANOVA (see Table 7) for the high comprehending Broca patients in the 600- to 1200-msec latency range revealed a significant main effect of agreement for the midline electrode sites. The ANOVA for the low comprehending Broca patients (see Table 8) did not lead to any significant effect of agreement.

Figure 8 presents data of individual subjects. This figure shows per subject the effect size in the 600- to 1200-msec epoch, collapsed over the conjoined and 
Table 3. Subject-Verb Agreement Violations for RH Patients: Mean ERP Amplitude ANOVAs in the 600- to 1200-msec Latency Range following the Onset of the Critical Word

\begin{tabular}{lcccc}
\hline Source & $d f$ & $F$ & SEM & $p$ \\
\hline Omnibus ANOVA (13 electrodes) & & & \\
Complexity & 1,4 & 0.12 & 11.71 & .743 \\
Agreement & 1,4 & 6.20 & 2.84 & .067 \\
Compl $\times$ Agree & 1,4 & 0.01 & 2.33 & .921 \\
Compl $\times \mathrm{El}$ & $3.20,12.82$ & 1.78 & 1.27 & .199 \\
Agree $\times \mathrm{El}$ & 12,48 & 2.71 & 0.62 & $.007^{* *}$ \\
Compl $\times$ Agree $\times \mathrm{El}$ & $4.12,16.50$ & 1.46 & 0.56 & 0.258
\end{tabular}

Midline ANOVA (3 electrodes)

$\begin{array}{lcccc}\text { Complexity } & 1,4 & 1.24 & 2.32 & .328 \\ \text { Agreement } & 1,4 & 1.92 & 3.27 & .238 \\ \text { Compl } \times \text { Agree } & 1,4 & 4.30 & 0.65 & .107 \\ \text { Compl } \times \text { El } & 1.20,4.82 & 0.71 & 1.06 & .465 \\ \text { Agree } \times \text { El } & 2,8 & 7.66 & 0.37 & .014^{*} \\ \text { Compl } \times \text { Agree } \times \mathrm{El} & 1.94,7.76 & 0.36 & 0.49 & .705\end{array}$

Posterior ANOVA (5 electrodes)

$\begin{array}{lcrrc}\text { Complexity } & 1,4 & 0.04 & 12.49 & .848 \\ \text { Agreement } & 1,4 & 13.64 & 2.23 & .021^{*} \\ \text { Compl } \times \text { Agree } & 1,4 & 0.46 & 4.38 & .535 \\ \text { Compl } \times \mathrm{El} & 1.31,5.22 & 2.79 & 0.54 & .153 \\ \text { Agree } \times \mathrm{El} & 4,16 & 2.00 & 0.46 & .143 \\ \text { Compl } \times \text { Agree } \times \mathrm{El} & 4,16 & 0.90 & 0.35 & .489\end{array}$

Lateral ANOVA $(2 \times 5$ electrodes $)$

\begin{tabular}{lcccc} 
Complexity & 1,4 & 0.02 & 9.69 & .893 \\
Agreement & 1,4 & 12.54 & 0.93 & $.024^{*}$ \\
Compl $\times$ Agree & 1,4 & 0.54 & 2.25 & .504 \\
Compl $\times \mathrm{El}$ & $2.28,9.13$ & 0.54 & 1.97 & .621 \\
Agree $\times \mathrm{El}$ & $2.03,8.13$ & 7.47 & 0.44 & $.014^{*}$ \\
Compl $\times$ Hemi & 1,4 & 5.05 & 3.71 & .088 \\
Agree $\times$ Hemi & 1,4 & 0.39 & 2.47 & .565 \\
Compl $\times$ Agree $\times$ Hemi & 1,4 & 0.23 & 1.71 & .658 \\
\hline Compl $=$ complexity (conjoined vs. embedded); Agree $=$ subject-verb \\
agreement (correct vs. incorrect); El = electrode; Hemi $=$ hemisphere. \\
$* p<0.05$. \\
$\begin{array}{l}* * 0 \\
* 0.01 .\end{array}$
\end{tabular}

embedded sentences, and averaged over five posterior electrode sites (Pz, LTP, RTP, PO7, PO8), where P600/SPS effects are maximal. As is clear from this figure, there is considerable variation in the size of the agreement effect within all of the subject groups. However, all normal control subjects except one showed a P600/SPS effect. A P600/SPS effect was present in all RH patients. Thus, the overall pattern of results that was observed in the averaged data was present in most control and RH subjects.

The Broca patients showed a less consistent pattern. Only 6 of the 10 patients showed a P600/SPS effect. For the other patients, the effect size either rendered a negative value or was near zero. This variable performance is compatible with the overall absence of a significant effect of agreement. Four high comprehending Broca patients showed a P600/SPS effect. This in contrast to the subgroup with a relatively more severe syntactic comprehension impairment in which only two patients showed a P600/SPS effect of some size.

\section{Tone Oddball Task}

Artefact rejection and correction procedures were identical to the ones used for the sentence ERPs, in a critical window that ranged from $150 \mathrm{msec}$ before onset of the tone to $850 \mathrm{msec}$ after tone onset. The overall rejection rate was $19.9 \%$ for the normal control subjects, $19.2 \%$ for the $\mathrm{RH}$ patients, and $11.8 \%$ for the aphasic patients. For each subject, average waveforms were computed across all remaining trials per condition (rare vs. frequent tones), after normalizing the individual trial ERPs on the basis of a 150-msec prestimulus baseline. Statistical analyses on P300 effects were performed on the mean amplitudes in the latency range of 250-500 msec.

Table 4. Subject-Verb Agreement Violations for RH Patients: Mean ERP Amplitude ANOVAs in the 400- to 600-msec Latency Range following the Onset of the Critical Word

\begin{tabular}{lcccc}
\hline Source & $d f$ & $F$ & SEM & $p$ \\
\hline Anterior ANOVA $(2 \times 2$ electrodes $)$ & & & \\
Complexity & 1,4 & 0.86 & 6.08 & .406 \\
Agreement & 1,4 & 0.41 & 2.05 & .559 \\
Compl $\times$ Agree & 1,4 & 5.09 & 1.92 & .087 \\
Compl $\times$ El & 1,4 & 0.61 & 0.86 & .480 \\
Agree $\times$ El & 1,4 & 0.39 & 0.06 & .565 \\
Compl $\times$ Hemi & 1,4 & 1.13 & 0.82 & .348 \\
Agree $\times$ Hemi & 1,4 & 0.02 & 1.56 & .892 \\
Compl $\times$ Agree $\times$ Hemi & 1,4 & 0.81 & 0.14 & .418 \\
\hline Compl $~$ & complexi $($ Conjor
\end{tabular}

Compl $=$ complexity $($ conjoined vs. embedded $) ;$ Agree $=$ subject-verb agreement (correct vs. incorrect); $\mathrm{El}=$ electrode; Hemi $=$ hemisphere. 
Figure 6. Grand average ERP waveforms for the group of Broca patients $(n=10)$ elicited by critical correct words (solid line) or incorrect words (dotted line) in the subject-verb agreement (conjoined) condition. The onset of the $\mathrm{CW}$ is at $0 \mathrm{msec}$.

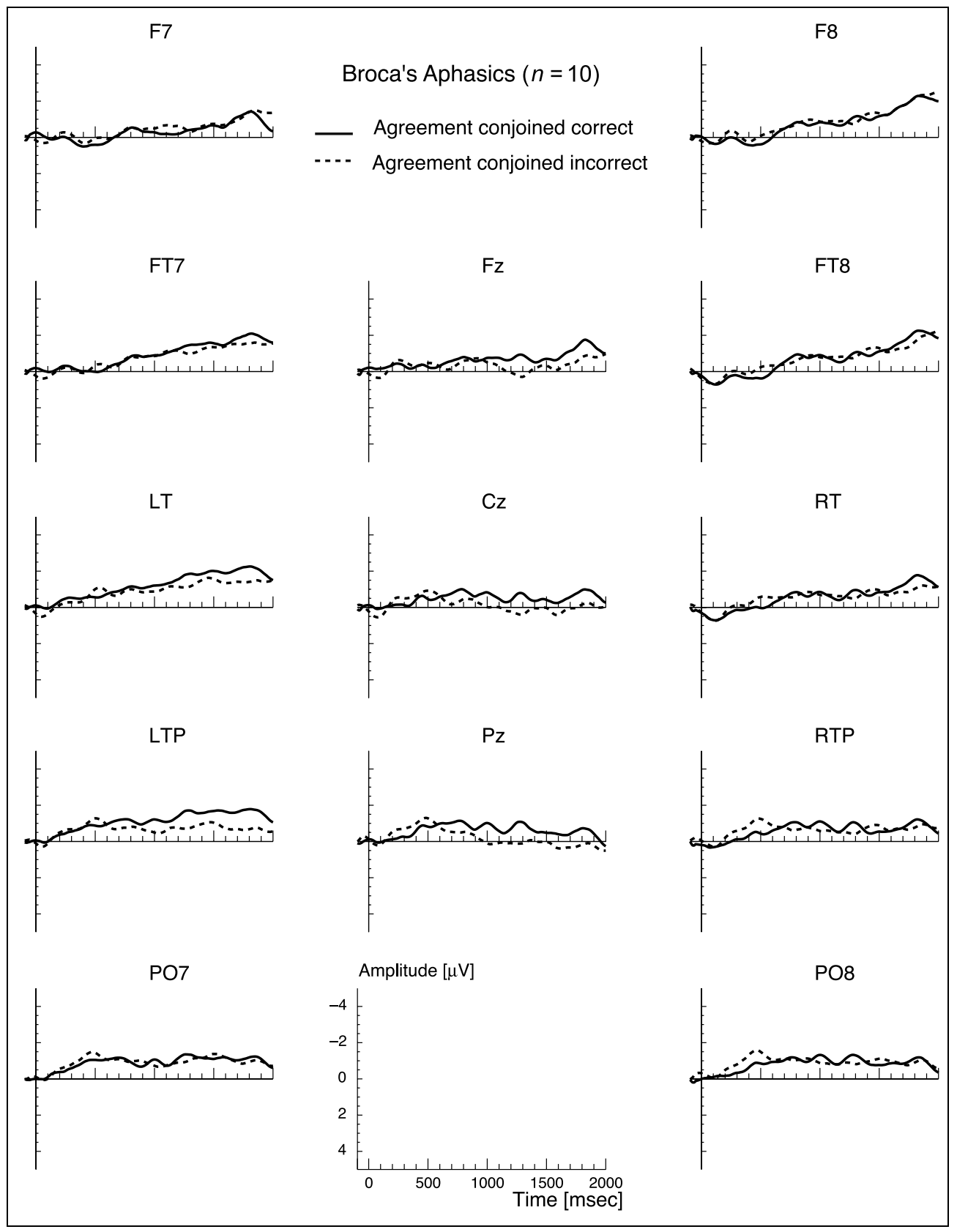

Figure 9 summarizes the P300 effects by means of the difference waveforms. Table 9 summarizes the statistical analyses. For the normal control subjects a significant P300 effect $(4.20 \mu \mathrm{V})$ was obtained, with a characteristic centroparietal distribution. Also, the P300 effect $(3.13 \mu \mathrm{V})$ for the RH patients was significant and did not differ from the normal controls, as indicated by the absence of a significant group by tones interaction. Likewise, the overall P300 effect in the Broca patients was significant and corresponded to a $2.55 \mu \mathrm{V}$ amplitude difference. Although the size of the effect in the Broca patients was somewhat reduced relative to the normal controls, the group by tones interaction was not significant. When testing high Comprehenders against low Compre- henders no significant group of patients by tones interaction was obtained.

Figure 10 shows tone oddball data of individual subjects. All normal control subjects, all RH patients, and eight of the 10 Broca patients showed P300 effects, which varied in size. Two Broca patients showed more negative waveforms to the rare tones than to the frequent tones. Such opposite P300 effects have been reported before (Swaab, Brown, \& Hagoort, 1997; Hagoort, Brown, \& Swaab, 1996). It has been suggested that such an abnormal P300 effect might be related to the inability to count. One of the patients who showed this abnormal P300 effect (subject 10) was indeed unable to count. 
Figure 7. Grand average ERP waveforms for the group of Broca patients $(n=10)$ elicited by critical correct words (solid line) or incorrect words (dotted line) in the subject-verb agreement (embedded) condition. The onset of the $\mathrm{CW}$ is at $0 \mathrm{msec}$.

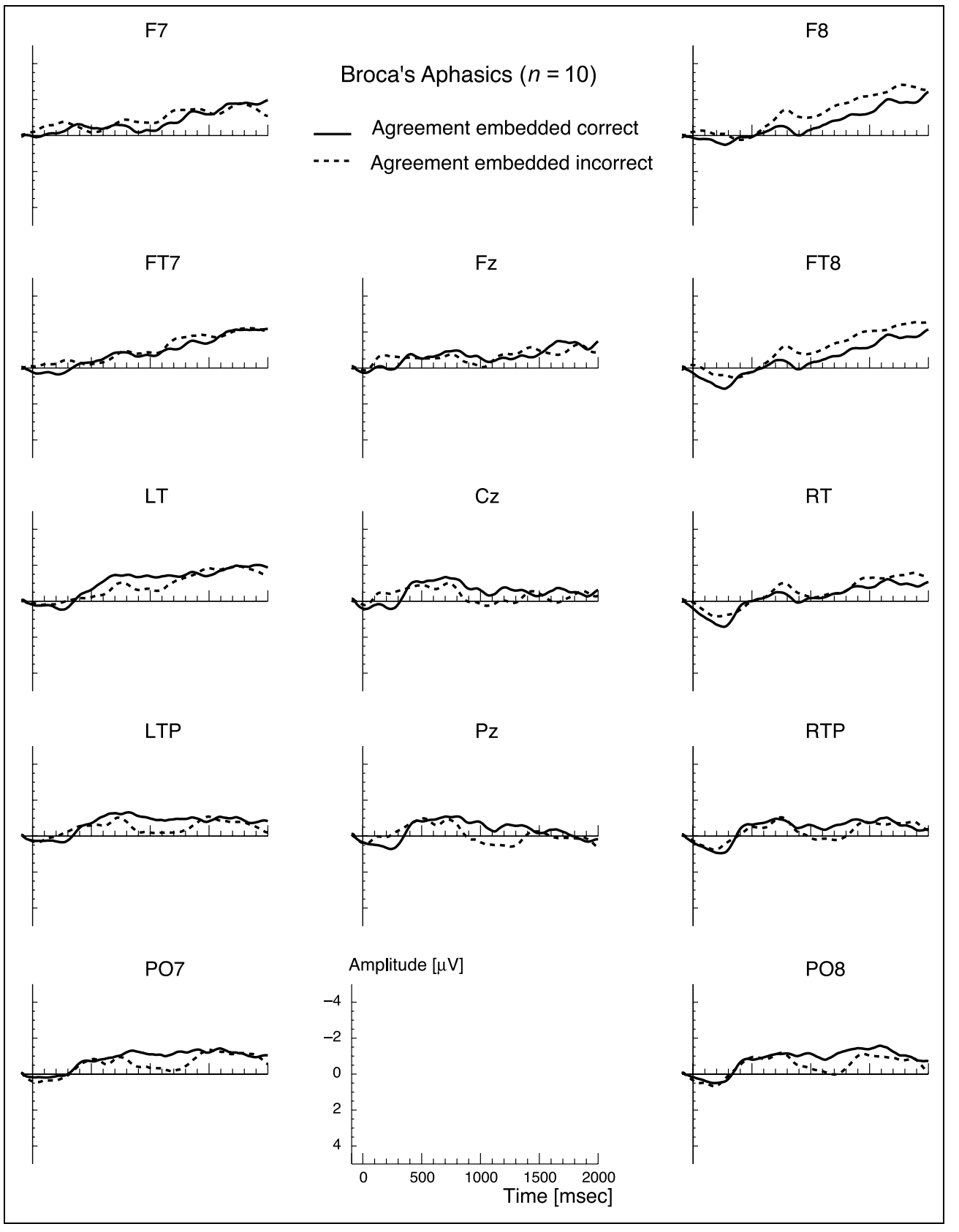

\section{Questionnaire}

The normal controls answered of 98\% of the questions correctly (range: 91-100\%). For the other groups the scores were $96 \%$ for the RH patients (range: 92-100\%) and $89 \%$ for the Broca patients (range: 63-100\%). These results indicate that the subjects were engaged in attentive listening to the sentences.

\section{DISCUSSION}

The aim of the present study was to investigate syntactic information processing during auditory sentence comprehension in patients with Broca's aphasia. For that purpose ERPs were recorded while subjects listened to sentences that were either syntactically correct or contained violations of subject-verb agreement. The central questions were: First, do the Broca patients show sensitivity to subject-verb agreement violations as indicated by a P600/SPS effect? Second, does the severity of the syntactic comprehension impairment in the Broca patients affect the ERP responses?

To summarize the results, Figure 11 presents for the three different subject groups an overlay of the difference waveforms for the conjoined and embedded sentences. Difference waveforms reflect the size of an effect and are obtained by subtracting the correct condition from the violated one. 
Table 5. Subject-Verb Agreement Violations for Broca Patients: Mean ERP Amplitude ANOVAs in the 600- to 1200msec Latency Range following the Onset of the Critical Word

\begin{tabular}{lcrrr}
\hline Source & $d f$ & $F$ & SEM & $p$ \\
\hline Omnibus ANOVA (13 electrodes) & & & \\
Complexity & 1,9 & 0.03 & 14.09 & .873 \\
Agreement & 1,9 & 0.70 & 7.14 & .423 \\
Compl $\times$ Agree & 1,9 & 0.01 & 15.05 & .920 \\
Compl $\times$ El & $6.65,59.84$ & 0.44 & 0.51 & .863 \\
Agree $\times$ El & $3.07,27.60$ & 1.60 & 0.87 & .212 \\
Compl $\times$ Agree $\times \mathrm{El}$ & $3.99,35.93$ & 0.59 & 0.68 & .669
\end{tabular}

Midline ANOVA (3 electrodes)

$\begin{array}{lllll}\text { Complexity } & 1,9 & 0.00 & 7.07 & .981 \\ \text { Agreement } & 1,9 & 1.30 & 5.63 & .284 \\ \text { Compl } \times \text { Agree } & 1,9 & 0.00 & 5.10 & .949 \\ \text { Compl } \times \mathrm{El} & 2,18 & 0.37 & 0.17 & .694 \\ \text { Agree } \times \mathrm{El} & 1.35,12.19 & 0.96 & 0.47 & .374 \\ \text { Compl } \times \text { Agree } \times \mathrm{El} & 1.22,10.99 & 0.25 & 0.70 & .677\end{array}$

Posterior ANOVA (5 electrodes)

\begin{tabular}{lllll} 
Complexity & 1,9 & 0.12 & 8.23 & .734 \\
Agreement & 1,9 & 0.94 & 8.25 & .358 \\
Compl $\times$ Agree & 1,9 & 0.06 & 5.20 & .815 \\
Compl $\times \mathrm{El}$ & $3.14,28.28$ & 0.13 & 0.50 & .947 \\
Agree $\times \mathrm{El}$ & $3.08,27.73$ & 1.55 & 0.25 & .222 \\
Compl $\times$ Agree $\times \mathrm{El}$ & $2.61,23.51$ & 0.44 & 0.58 & .704 \\
& & & & \\
Lateral ANOVA $(2 \times 5$ electrodes $)$ & & & \\
Complexity & 1,9 & 0.05 & 8.53 & .825 \\
Agreement & 1,9 & 0.34 & 3.46 & .576 \\
Compl $\times$ Agree & 1,9 & 0.03 & 10.26 & .870 \\
Compl $\times$ El & $1.75,15.73$ & 0.87 & 0.52 & .411 \\
Agree $\times$ El & $1.33,11.97$ & 1.11 & 1.24 & .335 \\
Compl $\times$ Hemi & 1,9 & 0.86 & 0.64 & .377 \\
Agree $\times$ Hemi & 1,9 & 3.01 & 1.82 & .117 \\
Compl $\times$ Agree $\times$ Hemi & 1,9 & 0.75 & 2.73 & .409 \\
\hline Compl $=$ complexiy & & & &
\end{tabular}

Compl $=$ complexity $($ conjoined vs. embedded $) ;$ Agree $=$ subject-verb agreement (correct vs. incorrect); $\mathrm{El}=$ electrode; Hemi $=$ hemisphere.
Table 6. Between-Subjects ANOVAs for Subject-Verb Agreement Violations on Mean ERP Amplitude in Specified Latency Ranges following the Onset of the Critical Word

\begin{tabular}{lccrc}
\hline Source & $d f$ & $F$ & SEM & $p$ \\
\hline $\begin{array}{l}\text { Normal controls versus RH patients } \\
\text { omnibus ANOVA }\end{array}$ & (13 electrodes) & & & \\
Group & 1,15 & 0.40 & 46.73 & .537 \\
Complexity & 1,15 & 0.42 & 11.64 & .527 \\
Group $\times$ Complexity & 1,15 & 1.54 & 11.64 & .234 \\
Agreement & 1,15 & 15.60 & 9.30 & $.001^{* * *}$ \\
Group $\times$ Agreement & 1,15 & 2.68 & 9.30 & .123 \\
Group $\times$ Compl $\times$ Agree & 1,15 & 0.77 & 2.19 & .395
\end{tabular}

Normal controls versus RH patients 400-600-msec: anterior ANOVA (4 electrodes)

$\begin{array}{lcccc}\text { Group } & 1,15 & 0.10 & 13.69 & .756 \\ \text { Complexity } & 1,15 & 0.74 & 5.34 & .404 \\ \text { Group } \times \text { Complexity } & 1,15 & 6.36 & 5.34 & .023^{*} \\ \text { Agreement } & 1,15 & 0.31 & 2.61 & .584 \\ \text { Group } \times \text { Agreement } & 1,15 & 2.28 & 2.61 & .152 \\ \text { Group } \times \text { Compl } \times \text { Agree } & 1,15 & 4.94 & 1.52 & .042^{*}\end{array}$

Normal controls versus Broca patients 600-1200-msec: omnibus ANOVA (13 electrodes)

\begin{tabular}{lrrrl} 
Group & 1,20 & 7.72 & 36.24 & $.012^{*}$ \\
Complexity & 1,20 & 1.56 & 12.73 & .226 \\
Group $\times$ Complexity & 1,20 & 0.99 & 12.73 & .332 \\
Agreement & 1,20 & 15.58 & 9.62 & $.001^{* * *}$ \\
Group $\times$ Agreement & 1,20 & 8.29 & 9.62 & $.009^{* *}$ \\
Group $\times$ Compl $\times$ Agree & 1,20 & 0.38 & 7.95 & .544 \\
& & & & \\
High comprehenders versus low comprehenders & \\
$\quad$ 600-1200-msec: midline ANOVA (3 & electrodes) & \\
Group & 1,8 & 0.56 & 13.58 & .474 \\
Complexity & 1,8 & 0.00 & 6.10 & .979 \\
Group $\times$ Complexity & 1,8 & 2.43 & 6.10 & .158 \\
Agreement & 1,8 & 2.08 & 3.51 & .188 \\
Group $\times$ Agreement & 1,8 & 6.43 & 3.51 & $.035^{*}$ \\
Group $\times$ Compl $\times$ Agree & 1,8 & 0.55 & 5.38 & .481 \\
\hline
\end{tabular}

Compl $=$ complexity $($ conjoined vs. embedded); Agree $=$ subject-verb agreement (correct vs. incorrect); $\mathrm{El}=$ electrode; $\mathrm{Hemi}=$ hemisphere

$* p<0.05$.

$* * p<0.01$.

$* * * p \leq 0.001$. 
Table 7. Subject-Verb Agreement Violations for High Comprehending Broca Patients: Mean ERP Amplitude ANOVAs in the 600- to 1200-msec Latency Range following the Onset of the Critical Word

\begin{tabular}{lllll}
\hline Source & $d f$ & $F$ & $S E M$ & $p$ \\
\hline
\end{tabular}

Omnibus ANOVA (13 electrodes)

$\begin{array}{lllll}\text { Complexity } & 1,4 & 1.88 & 3.91 & .242 \\ \text { Agreement } & 1,4 & 3.53 & 5.65 & .133 \\ \text { Compl } \times \text { Agree } & 1,4 & 1.36 & 3.07 & .308 \\ \text { Compl } \times \mathrm{El} & 9.27,37.06 & 0.77 & 0.54 & .650 \\ \text { Agree } \times \mathrm{El} & 2.04,8.15 & 4.93 & 0.59 & .039^{*} \\ \text { Compl } \times \text { Agree } \times \mathrm{El} & 5.20,20.79 & 0.80 & 0.19 & .568\end{array}$

Midline ANOVA (3 electrodes)

$\begin{array}{llrll}\text { Complexity } & 1,4 & 2.84 & 2.52 & .167 \\ \text { Agreement } & 1,4 & 12.85 & 2.16 & .023^{*} \\ \text { Compl } \times \text { Agree } & 1,4 & 1.51 & 1.15 & .287 \\ \text { Compl } \times \mathrm{El} & 2,18 & 0.37 & 0.17 & .694 \\ \text { Agree } \times \mathrm{El} & 2,8 & 3.33 & 0.08 & .089 \\ \text { Compl } \times \text { Agree } \times \mathrm{El} & 2,8 & 1.37 & 0.16 & .308\end{array}$

Posterior ANOVA (5 electrodes)

\begin{tabular}{lllll} 
Complexity & 1,4 & 0.65 & 3.22 & .466 \\
Agreement & 1,4 & 3.58 & 8.26 & .131 \\
Compl $\times$ Agree & 1,4 & 0.06 & 2.11 & .812 \\
Compl $\times \mathrm{El}$ & 4,16 & 1.38 & 0.40 & .286 \\
Agree $\times \mathrm{El}$ & $2.32,9.26$ & 2.93 & 0.17 & .098 \\
Compl $\times$ Agree $\times \mathrm{El}$ & $2.17,8.68$ & 0.13 & 0.19 & .894 \\
& & & & \\
Lateral ANOVA $(2 \times 5$ electrodes $)$ & & & & \\
Complexity & 1,4 & 1.34 & 1.96 & .311 \\
Agreement & 1,4 & 1.27 & 3.83 & .322 \\
Compl $\times$ Agree & 1,4 & 1.22 & 2.13 & .332 \\
Compl $\times$ El & $1.63,6.53$ & 0.46 & 0.79 & .612 \\
Agree $\times$ El & $1.09,4.35$ & 3.65 & 1.22 & .123 \\
Compl $\times$ Hemi & 1,4 & 0.55 & 0.57 & .498 \\
Agree $\times$ Hemi & 1,4 & 2.11 & 0.75 & .220 \\
Compl $\times$ Agree $\times$ Hemi & 1,4 & 0.36 & 0.55 & .581 \\
\hline
\end{tabular}

Compl $=$ complexity $($ conjoined vs. embedded $) ;$ Agree $=$ subject-verb agreement (correct vs. incorrect); $\mathrm{El}=$ electrode; Hemi = hemisphere. $* p<.05$.
Table 8. Subject-Verb Agreement Violations for Low Comprehending Broca Patients: Mean ERP Amplitude ANOVAs in the 600- to 1200-msec Latency Range following the Onset of the Critical Word

\begin{tabular}{lcccc}
\hline Source & $d f$ & $F$ & SEM & $p$ \\
\hline Omnibus ANOVA (13 electrodes) & & & \\
Complexity & 1,4 & 0.56 & 22.85 & .496 \\
Agreement & 1,4 & 0.27 & 6.26 & .632 \\
Compl $\times$ Agree & 1,4 & 0.24 & 28.09 & .648 \\
Compl $\times$ El & $5.14,20.54$ & 1.17 & 0.44 & .359 \\
Agree $\times$ El & $4.97,19.86$ & 0.92 & 0.81 & .488 \\
Compl $\times$ Agree $\times$ El & $5.57,22.26$ & 0.50 & 1.25 & .790
\end{tabular}

Midline ANOVA (3 electrodes)

$\begin{array}{lllll}\text { Complexity } & 1,4 & 0.79 & 9.69 & .424 \\ \text { Agreement } & 1,4 & 0.43 & 4.86 & .547 \\ \text { Compl } \times \text { Agree } & 1,4 & 0.13 & 9.60 & .739 \\ \text { Compl } \times \mathrm{El} & 1.98,7.94 & 1.55 & 0.18 & .269 \\ \text { Agree } \times \mathrm{El} & 1.39,5.54 & 0.04 & 0.60 & .912 \\ \text { Compl } \times \text { Agree } \times \mathrm{El} & 1.32,5.30 & 0.99 & 1.13 & .392\end{array}$

Posterior ANOVA (5 electrodes)

$\begin{array}{lllll}\text { Complexity } & 1,4 & 0.63 & 12.99 & .471 \\ \text { Agreement } & 1,4 & 0.53 & 4.27 & .507 \\ \text { Compl } \times \text { Agree } & 1,4 & 0.14 & 9.30 & .727 \\ \text { Compl } \times \mathrm{El} & 4,16 & 1.11 & 0.48 & .384 \\ \text { Agree } \times \mathrm{El} & 4,16 & 0.67 & 0.31 & .691 \\ \text { Compl } \times \text { Agree } \times \mathrm{El} & 3.70,14.80 & 0.38 & 1.06 & .807\end{array}$

Lateral ANOVA $(2 \times 5$ electrodes $)$

\begin{tabular}{lllll} 
Complexity & 1,4 & 0.44 & 15.02 & .544 \\
Agreement & 1,4 & 0.16 & 2.91 & .710 \\
Compl $\times$ Agree & 1,4 & 0.30 & 18.98 & .615 \\
Compl $\times \mathrm{El}$ & $2.69,10.77$ & 0.66 & 0.35 & .578 \\
Agree $\times \mathrm{El}$ & $3.15,12.62$ & 1.32 & 0.60 & .313 \\
Compl $\times$ Hemi & 1,4 & 9.24 & 0.28 & $.038^{*}$ \\
Agree $\times$ Hemi & 1,4 & 1.28 & 3.26 & .321 \\
Compl $\times$ Agree $\times$ Hemi & 1,4 & 0.46 & 5.44 & .536 \\
\hline
\end{tabular}

Compl $=$ complexity $($ conjoined vs. embedded $)$; Agree $=$ subject-verb agreement (correct vs. incorrect); $\mathrm{El}=$ electrode; Hemi $=$ hemisphere $* p<.05$. 


\section{Individual Subject Data Subject-Verb Agreement Violations}
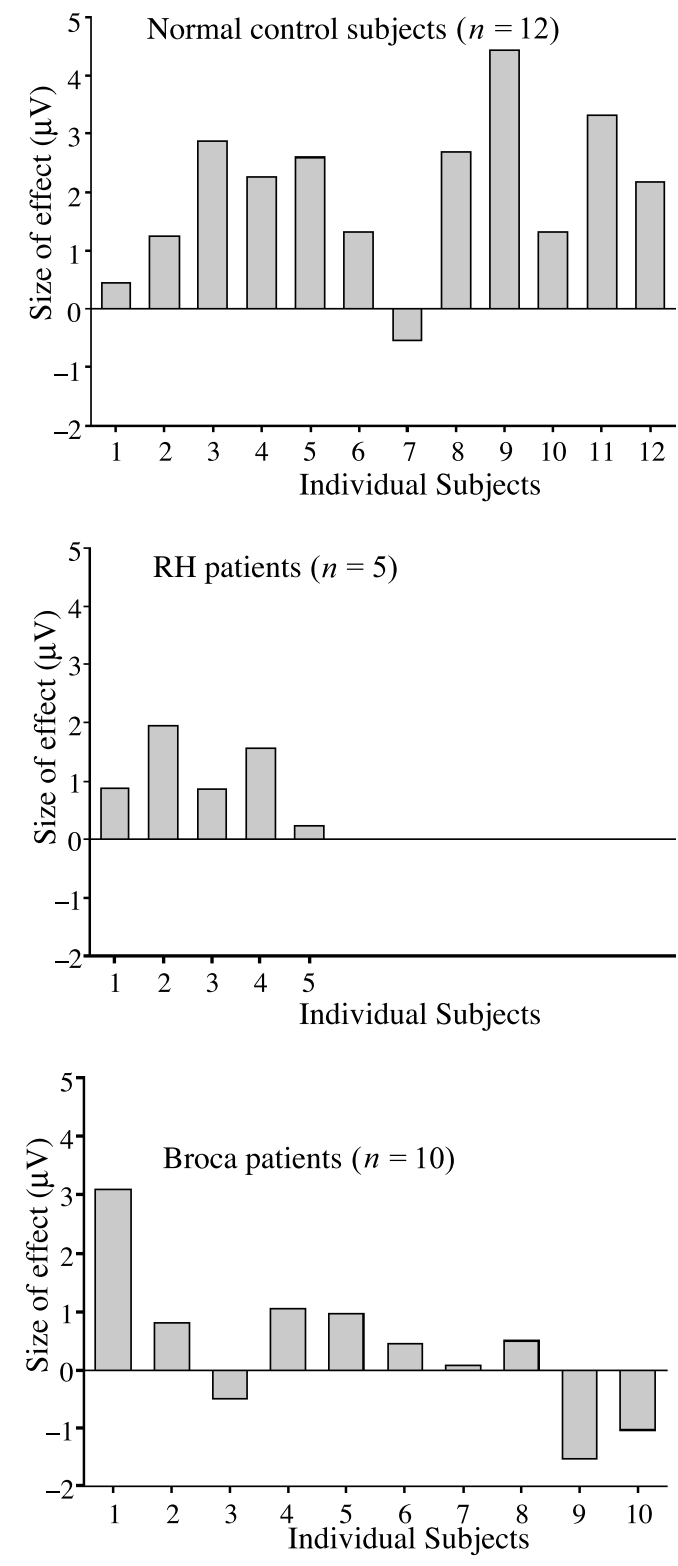

Figure 8. Mean amplitude of the grammaticality effect in microvolts (collapsed over conjoined and embedded sentences) over five posterior electrode sites (latency: 600-1200 msec), for each individual subject. High comprehending Broca patients correspond with Broca patients $1-5$ in Table 10 , low comprehending patients with subject numbers $6-10$ in the same table.

The age-matched normal controls showed the expected P600/SPS effect to the agreement violations for both the conjoined and embedded sentences. Although the P600/SPS effect in the embedded condition was somewhat smaller in amplitude, the effect for the embedded condition was statistically indistinguishable from the conjoined condition. Thus, the normal controls were sensitive to these violations, irrespective of syntactic complexity.

The nonaphasic patients with a lesion in the right hemisphere showed essentially the same pattern of P600/SPS effects to these syntactic violations. Although the size of the effect in the embedded condition seemed reduced when compared to the conjoined condition, this difference did not turn out to be significant. Even though the size of the P600/SPS was reduced relative to the normal controls, averaged over electrodes this difference was not statistically significant. These results indicate that there were no qualitative differences in the pattern of results for the normal controls and the RH patients. Thus, relatively normal P600/SPS effects can be obtained in brain-damaged patients without aphasia. This is not to say that a lesion in the right hemisphere will never have its impact on syntactic sentence understanding. A study of Caplan, Hildebrandt, and Makris (1996), for instance, showed significantly lower performance for syntactically complex sentences in right-hemisphere patients than in normal control subjects. In a meta-analysis of neuroimaging studies on syntactic processing (in healthy subjects), right-hemisphere activation was found on repeated occasions (Indefrey, 2001). The right posterior inferior frontal gyrus became active during the processing of syntactically more complex sentences. These studies indicate that there might be some right-hemisphere involvement in auditory syntactic processing. However, the presence of P600/SPS effects in the RH patients of our study seems to suggest that the processing of subject-verb agreement relations is relatively undisrupted in these patients.

In contrast to the control groups, the overall group of Broca patients did not show clear P600/SPS effects in response to the subject-verb agreement violations. The effects were absent for both the conjoined and the embedded sentences. These findings thus suggest that these Broca patients, unlike the normal control subjects and the RH patients, did not show the same on-line sensitivity as their controls to these types of violations. The absence of P600/SPS effects might be indicative of the difficulties that these patients experience with the processing of this type of syntactic dependency. To determine whether the absence of a P600/SPS effect can correctly be ascribed to an alteration in syntactic processing, rather than to a general effect of brain damage on cognitive ERP components, we need to discuss the P300 results of the control experiment.

Similar to the normal control subjects and RH patients, the group of Broca patients showed a significant P300 effect in the tone oddball condition. Furthermore, the size of the P300 effect was statistically indistinguishable from the effect of the controls. Since the Broca patients had a relatively normal P300 effect, it can be concluded that aphasia in itself does not lead to a general reduction in all cognitive ERP effects. Therefore, the absence of P600/SPS effects cannot be interpreted in terms of a general, aspecific lesion 
Figure 9. Grand average difference waveforms (oddballs minus standards) for normal control subjects (solid line), $\mathrm{RH}$ patients (dotted line), and Broca patients (dashed line).

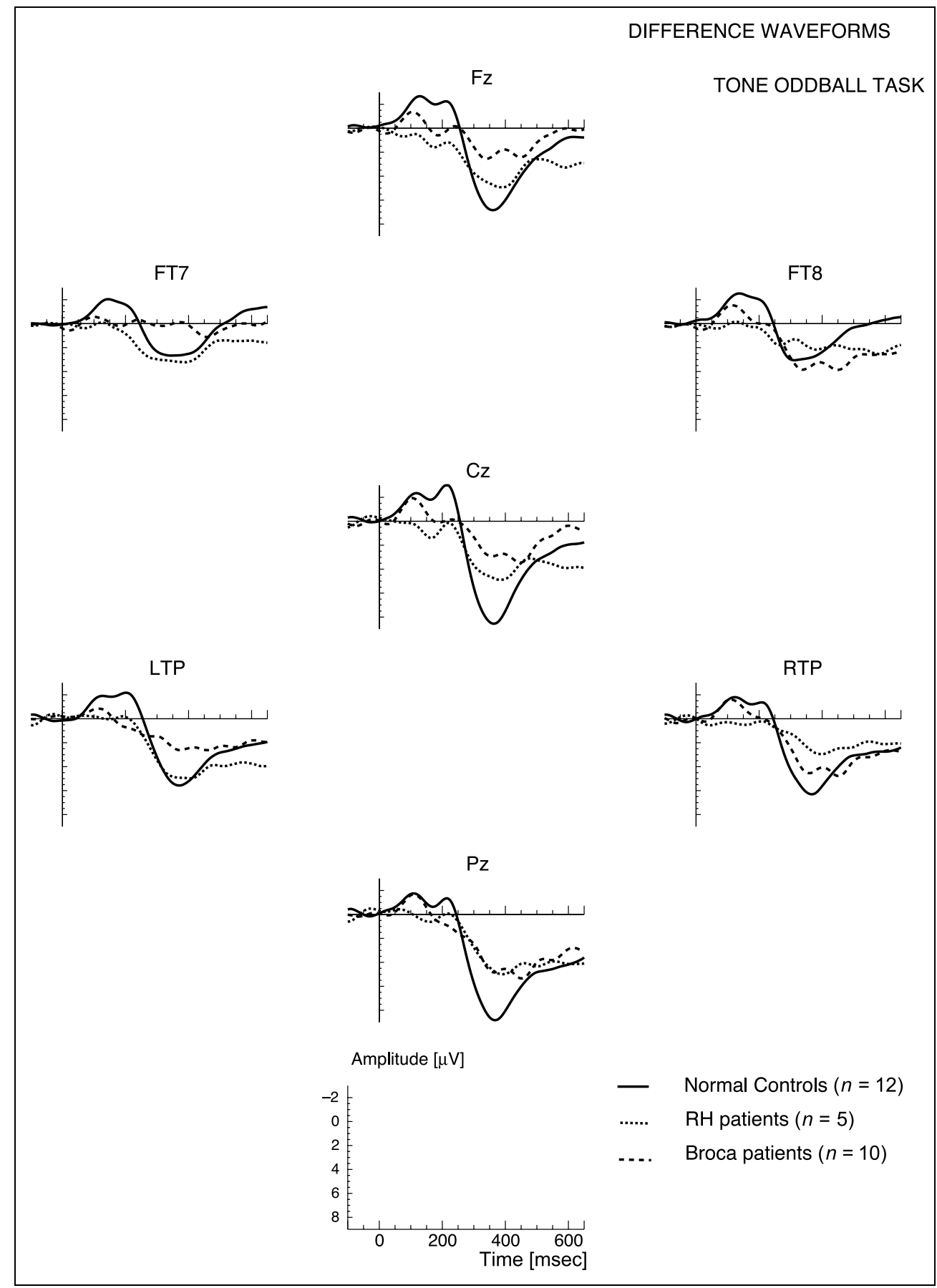

effect, equally affecting different endogenous ERP components. Overall then, it most likely reflects aspects of the underlying language processing deficit in the patients studied and not an aspecific effect of their brain damage.

The observed dissociation between the P300 and P600/SPS effect in these Broca patients is also interesting from the perspective of the P600/SPS-P300 debate. Some studies (e.g., Coulson, King, \& Kutas, 1998a; Gunter, Stowe, \& Mulder, 1997) have claimed that the P600/SPS belongs to the family of classical P300 effects.
The P600 component is viewed then as being identical to the $\mathrm{P} 3 \mathrm{~b}$, a broadly distributed positive-going component with a centroparietal maximum whose amplitude is sensitive to aspects of stimuli such as task relevance, salience, and probability. Osterhout and Hagoort (1999) have criticized this view. The fact that a P600/SPS effect and a P300 effect can summate (Osterhout, McKinnon, Bersick, \& Corey, 1996) has been put forward as an argument for the belief that the ERP response to syntactic anomalies is at least partially distinct from the ERP response to unexpected anomalies that do not involve a 
Table 9. ANOVAs for Tone Oddball Task: Mean ERP Amplitude in the 250- to 500-msec Latency Range

\begin{tabular}{|c|c|c|c|c|}
\hline Source & $d f$ & $F$ & SEM & $p$ \\
\hline \multicolumn{5}{|c|}{ Normal controls: omnibus ANOVA (7 electrodes) } \\
\hline Tones & 1,11 & 41.38 & 17.87 & $.000 * * *$ \\
\hline Tones $\times \mathrm{El}$ & $3.50,38.51$ & 11.46 & 1.46 & $.000^{* * * *}$ \\
\hline \multicolumn{5}{|c|}{ RH patients: omnibus ANOVA ( 7 electrodes) } \\
\hline Tones & 1,4 & 7.96 & 21.50 & $.048^{*}$ \\
\hline Tones $\times \mathrm{El}$ & $3.16,12.65$ & 2.35 & 0.87 & .119 \\
\hline \multicolumn{5}{|c|}{ Broca patients: omnibus ANOVA (7 electrodes) } \\
\hline Tones & 1,9 & 5.54 & 40.94 & $.043 *$ \\
\hline Tones $\times \mathrm{El}$ & $3.41,30.70$ & 2.54 & 3.11 & .068 \\
\hline \multicolumn{5}{|c|}{$\begin{array}{l}\text { Normal controls versus RH patients: omnibus ANOVA } \\
\quad \text { ( } 7 \text { electrodes) }\end{array}$} \\
\hline Group & 1,15 & 1.39 & 56.23 & .257 \\
\hline Tones & 1,15 & 35.17 & 18.84 & $.000^{* * * *}$ \\
\hline Group $\times$ Tones & 1,15 & 0.75 & 18.84 & .401 \\
\hline \multicolumn{5}{|c|}{$\begin{array}{l}\text { Normal controls versus Broca patients: omnibus ANOVA } \\
\quad \text { ( } 7 \text { electrodes) }\end{array}$} \\
\hline Group & 1,20 & 4.54 & 37.58 & $.046 *$ \\
\hline Tones & 1,20 & 30.70 & 28.25 & $.000^{* * * *}$ \\
\hline Group $\times$ Tones & 1,20 & 1.84 & 28.25 & .190 \\
\hline \multicolumn{2}{|c|}{$\begin{array}{l}\text { High comprehenders versus lo } \\
\text { ANOVA (7 electrodes) }\end{array}$} & ow con & prehenders: & omnibus \\
\hline Group & 1,8 & 4.55 & 12.64 & .065 \\
\hline Tones & 1,8 & 5.43 & 41.72 & $.048^{*}$ \\
\hline Group $\times$ Tones & 1,8 & 0.83 & 41.72 & .388 \\
\hline
\end{tabular}

Tones $=$ tone oddball condition; $\mathrm{El}=$ electrode

$* p<0.05$;

$* * * p \leq 0.001$.

grammatical violation. The finding of our study that a P600/SPS effect can be absent in the presence of a sound P300 effect favors the interpretation that the triggering conditions for the P600/SPS are more specific than a general surprise response (cf. Donchin, 1981), context updating, or other explanations in terms of task relevance, salience, and probability.

The overall group of Broca patients did not show online sensitivity to the subject-verb agreement violations.

\section{Individual Subject Data Tone Oddball Task}
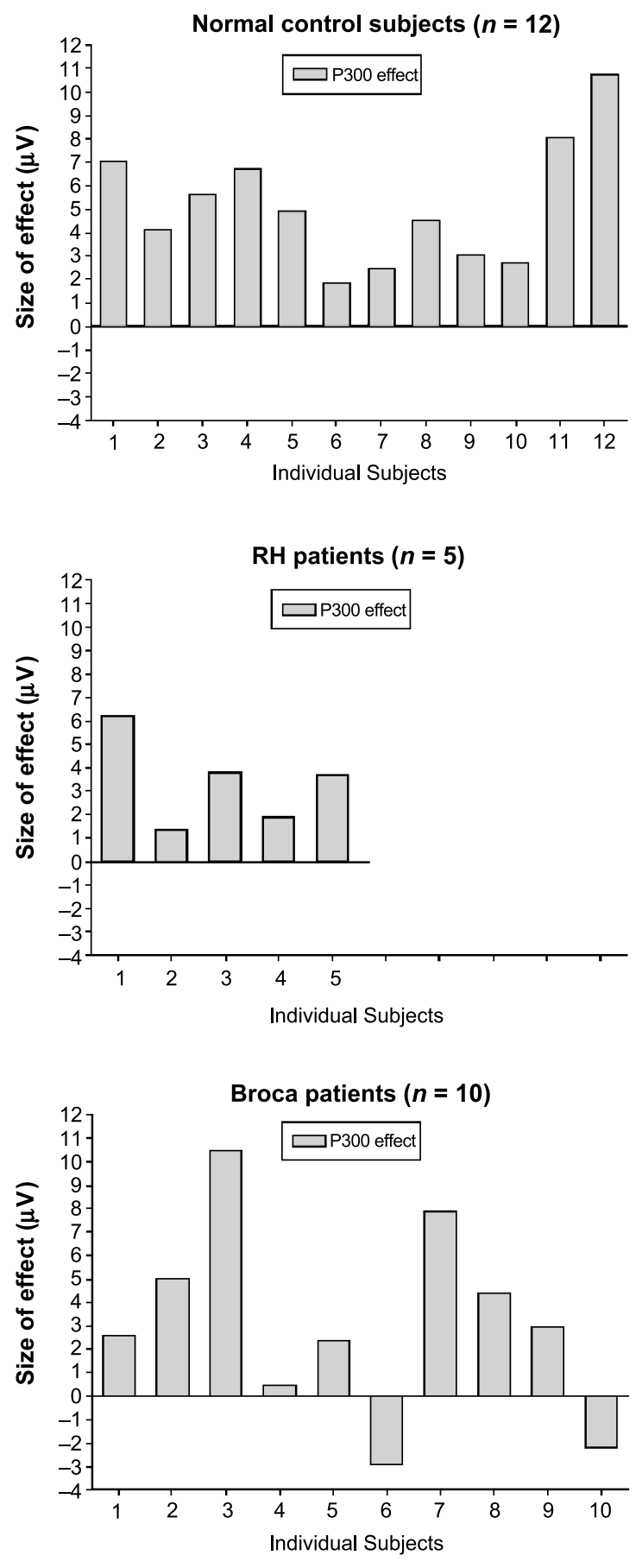

Figure 10. Mean amplitude of tone oddball effects in microvolts over four centroposterior electrodes (latency: 250-500 msec), for each individual subject. High comprehending Broca patients correspond with Broca patients 1-5 in Table 10, low comprehending patients with subject numbers 6-10 in the same table. 
Figure 11. Grand average difference waveforms for $\mathrm{Pz}$ (grammatically incorrect minus grammatically correct) for normal control subjects, $\mathrm{RH}$ patients, and Broca patients. Solid line for conjoined sentences, dashed line for embedded sentences.

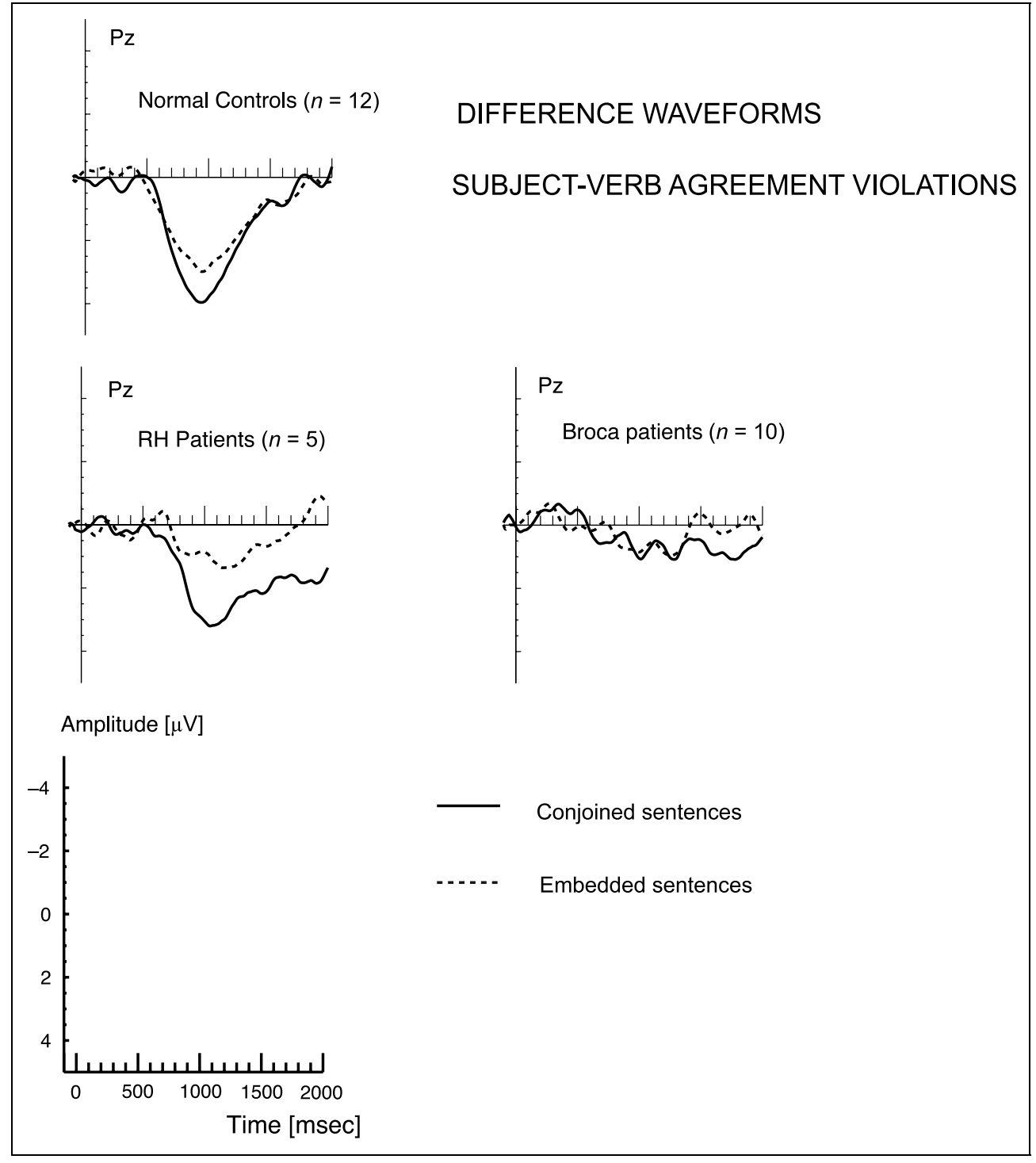

However, this sensitivity appeared to be modulated by the severity of the syntactic comprehension impairment. When the Broca patients were divided into two subgroups based on their performance on the syntactic offline test, the group of low comprehenders did not show an agreement effect at all. These patients seemed to experience difficulties with maintaining or exploiting the morphosyntactic number marking for establishing agreement. On the other hand, the group of high comprehenders showed an agreement effect, albeit reduced in comparison to the control subjects. This might suggest that the on-line sensitivity to this type of syntactic information as displayed by these patients was at least weakened. Thus, the severity of the syntactic comprehension impairment seemed to be reflected in the ERP response with the largest deviation from the normal P600/SPS effect for those patients with the most severe syntactic comprehension deficit.
Of special interest for our discussion is a study of Haarmann and Kolk (1994). They explored in Broca's aphasics the on-line sensitivity to almost the same type of subject-verb agreement violations as we used, by means of a word-monitoring paradigm. Our results for the elderly control subjects are consistent with the data of Haarmann and Kolk who also found an agreement effect in elderly controls (namely significantly faster monitoring latencies for a target word in agreeing than in nonagreeing sentences) irrespective of syntactic complexity. The Broca patients in their study showed an effect of agreement, which was mostly due to the simple sentences. This pattern of results contrasts with the absence of agreement effects in the data of our overall group of Broca patients. However, it clearly bears resemblance to our data of patients that suffered from a relatively less severe syntactic comprehension impairment. The authors describe the comprehension deficit 
of their Broca patients as mild, but no specific information is given about the level of severity of the syntactic comprehension impairment.

Before further discussing our results, it should be pointed out that we tried to tap the syntactic comprehension process as it unfolds in real time: The brain potentials were recorded while subjects listened to sentences without any additional task. There were no task demands such as, for instance, explicit error detection or word monitoring, except the very natural one of listening to speech. This situation approximates sentence processing under natural circumstances. Furthermore, the sentence materials were constructed in such a manner that nonsyntactic strategies to detect the subjectverb agreement violations would not be effective. Therefore, deviations from the standard P600/SPS effect as response to subject-verb agreement violations are most likely indicative of changes in on-line syntactic processing. Given the results of the questionnaire, it is very unlikely that deviations from the standard P600/SPS effect are due to a lack of attention to the auditory stimuli. On the contrary, the aphasic patients were well able to answer the questions as far as semantic aspects of the sentences were concerned.

What do our data imply for accounts of syntactic comprehension deficits in aphasia? It has been suggested that syntactic comprehension deficits in Broca's aphasics are due to changes in the temporal organization of the parsing process. Two kinds of temporal disturbance have been proposed: (1) The activation of syntactic information is slowed down (Friederici \& Kilborn, 1989; Haarmann \& Kolk, 1991b). (2) Syntactic information is subjected to a pathologically fast decay (Haarmann \& Kolk, 1994). Both disturbances can have a disruptive effect on the ability to coactivate sentencerepresentational elements. For instance, in the case of the sentences that we presented, number information not only needs to be extracted from the subject noun and the verb forms, but it has to be maintained long enough in verbal working memory to establish agreement between them. This requirement of computational simultaneity taxes verbal working memory both in terms of time and structure. In the auditory sentences of our study, the subject noun and the critical verb form were nonadjacent. The number information of the subject noun had to be available for some time before the relevant verb form information came in. If number information decays too fast, agreement cannot be established. At the same time, it is the phrasal configuration of the sentence that determines which elements should agree in number. More complex structures will tax memory stronger than simple structures. In this study, we did not find a complexity effect, presumably because the difference in complexity was not substantially enough to result in observable effects. Nevertheless, the data obtained allow some relevant conclusions about the nature of the syntactic comprehension problems in Broca's aphasics, especially in relation to the effect of severity of the impairment. Assuming that the degree of severity affects the processing problems in a quantitative (e.g., rate of decay) rather than a qualitative way, a few relevant conclusions can be drawn.

First, the data of the patients with the less severe syntactic comprehension impairment showed an agreement effect that was reduced in size, but nevertheless showed the same time course as the effects of the other subject groups. If it were a matter of too slow activation of number information, one should actually expect a shift in the onset latency of the effect. This was not the case for these patients. Second, the presence of an agreement effect in the high comprehenders suggests that morphosyntactic information is not lost, but can be extracted from the input. Third, the reduction of the agreement effect suggests that in these patients the online sensitivity to this type of structural information was weakened. Presumably, this is due to a too fast decay of the morphosyntactic number information. When arriving at the inflected verb, the subject noun phrase is checked for number (cf. Nicol, Forster, \& Veres, 1997), but due to decay, the mismatch between the number information will be no longer detected. This could then show up as a reduction in the ERP effect, or in the case of the more severely impaired patients even as an absence of the effect.

A too fast decay can result from reduced initial levels of activation, a faster than normal decay rate, or some combination of these two. Within the computational parsing model of Vosse and Kempen (2000), simulation of agrammatic parsing required that next to a faster decay rate, additional parameters had to be changed as well. These included the initial amount of activation and strength of inhibition (cf. Hagoort, 1993). Haarmann et al. (1997) assume in their computational account of aphasic sentence comprehension that Broca's aphasics have insufficient verbal working memory capacity to sustain normal comprehension performance. In this model, the degree of severity of the syntactic comprehension impairment varies with the amount of reduction in verbal working memory capacity. Results from simulation studies showed that the activation of elements at the beginning of a sentence rapidly decays over time, especially under the situation of low verbal working memory capacity (cf. Saffran, Dell, \& Schwartz, 2000). The data obtained in this study are compatible with both computational models of syntactic deficits in Broca's aphasia.

An alternative explanation for the absence of the effect in the low comprehenders, could be that these severely impaired patients have lost access to syntactic information. This interpretation cannot be excluded. However, differences in degree of severity are one of the key features of any group of aphasic patients. Therefore, we give preference to the account provided here because it explains these differences in degree of 
severity quite naturally and parsimoniously. Finally, when the same severely impaired patients were confronted with syntactic violations of word order, they did show an effect: Their waveforms were dominated by a meaning-related ERP effect (Hagoort, Wassenaar, \& Brown, 2003). The N400 effect for the word order violation suggests that these sentences were processed through a semantic compensatory processing route that was not available for the agreement violation.

\section{METHODS}

\section{Subjects}

Ten patients with aphasia secondary to a single cerebro vascular accident (CVA) in the left hemisphere participated in this study. A group of 12 healthy normal subjects, who were approximately matched in age and education level to the aphasic patients were tested to control for age and education effects. To account for nonspecific effects of brain damage on cognitive ERP components, a group of five nonaphasic patients with a single CVA in the right hemisphere (RH patients) was tested. All subjects gave informed consent, according to the declaration of Helsinki. The mean age of the aphasic patients was 59.8 years (range 42-74 years), the $\mathrm{RH}$ patients were on average 61.8 years (range $47-70$ years) and the normal controls had a mean age of 58.9 years (range 49-72 years). All elderly control subjects were right-handed according to an abridged version of the Oldfield Handedness Inventory (Oldfield, 1971). Five of the elderly control subjects reported familial left-handedness. The aphasic patients and the RH patients were premorbidly all right-handed. None of the elderly control subjects had any known neurological impairment or used neuroleptics. None of the control subjects reported hearing loss or memory problems.

All neurological patients were tested at least 9 months post onset of their CVA. All neurological patients were tested with the Dutch version of the Aachen Aphasia Test (AAT) (Graetz, De Bleser, \& Willmes, 1992). Both presence and type of aphasia were diagnosed on the basis of the test results and on the basis of a transcribed sample of their spontaneous speech. All RH patients were diagnosed as nonaphasic and all left-hemisphere patients were diagnosed as patients with Broca's aphasia. According to their scores on the comprehension subtest of the AAT, the aphasic patients had moderate to mild comprehension deficits. The presence of syntactic comprehension problems was determined by an off-line test that assesses the influence of syntactic complexity on sentence comprehension (Huber et al., 1993). The Dutch version (see, for a detailed description, Ter Keurs, Brown, Hagoort, \& Stegeman, 1999) contains five levels of syntactic complexity, ranging from active, semantically irreversible sentences, to sentences containing an embedded subject-relative clause in the passive voice (see Table 10). Patient's age, gender, results on the Token Test, scores on the AAT subtest on comprehension, overall scores on the syntactic off-line test and lesion site information are summarized in Table 11.

\section{Materials}

The materials for this experiment consisted of a list of 120 spoken sentence pairs. Half of each sentence pair was syntactically correct, half contained a violation of subject-verb number agreement. These number violations between nouns and verbs were couched in either relatively simple (60 sentence pairs) or relatively complex syntactic frames (60 sentence pairs), without changing word length or lexical content. An example is given in Table 12.

In the conjoined condition (see Table 12), the two verb phrases are expressed by a conjunction. In the embedded condition, one of the verb phrases is embedded in the subject noun phrase. The embedded sentence is more complex than its conjoined counterpart. The linguistic argumentation for the complexity difference relates to the depth of the phrasal configuration (Frazier, 1985), with the embedded sentence having a phrase structure that is one level deeper than the conjoined sentence (see Figure 12).

Following Haarmann and Kolk (1994), the sentences were constructed in such a way that nonsyntactic strategies to detect the subject-verb agreement violations would fail (see for details Haarmann et al., 1994). The violation always showed up at a midsentence position. The reason for this is twofold. We wanted the subjects to be fully engaged in the process of parsing before being confronted with a syntactic violation, and we wanted to avoid contamination of closure effects at sentence final position (cf. Hagoort et al., 1993).

An additional set of 260 sentences was used as practice and filler items. These contained semantic and syntactic violations (different from the present study) at varying positions in the sentence to prevent subjects from developing a strategy of predicting the position of an incorrect word.

A female speaker spoke all experimental sentences, fillers, and practice sentences at a normal speaking rate. Special care was taken to produce the ungrammatical sentences with a natural sentence melody. Sentences were spoken in a sound-attenuating booth, recorded on a digital audiotape, and stored on computer disk. A speech waveform editing system was used to mark the critical words and the onset and offset of each sentence.

The list of 240 experimental sentences was divided over two lists of 120 sentences each. Each list consisted of 60 correct and 60 incorrect experimental sentences. The 60 incorrect and the 60 correct sentences were made up of 30 sentences from the conjoined and 30 from the embedded condition. The members of a pair 
Table 10. Five Types of Sentences of the Dutch Syntactic Off-line Test and their Distracters

\begin{tabular}{|c|c|}
\hline Degree of syntactic complexity & Sentence \\
\hline I & $\begin{array}{l}\text { Active, semantically irreversible sentences, e.g., "Het meisje met de } \\
\text { strik draagt de bal." (The girl with the ribbon carries the ball.) }\end{array}$ \\
\hline II & $\begin{array}{l}\text { Active, semantically reversible sentences, e.g., "De man met de } \\
\text { bal zoekt het kind." (The man with the ball is looking for the child.) }\end{array}$ \\
\hline III & $\begin{array}{l}\text { Simple passive sentences, e.g., "De man met de bal wordt door het } \\
\text { kind gezocht." (The man with the ball is being looked for by the child.) }\end{array}$ \\
\hline IV & $\begin{array}{l}\text { Sentences with an active subject relative clause, e.g., "Het kind dat } \\
\text { naar de man zoekt, heeft een bal." (The child that is looking for the } \\
\text { man has a ball.) }\end{array}$ \\
\hline $\mathrm{V}$ & $\begin{array}{l}\text { Sentences with a passive subject relative clause, e.g., "Het kind dat } \\
\text { door de man gezocht wordt heeft een bal." (The child that is being } \\
\text { looked for by the man has a ball.) }\end{array}$ \\
\hline Type of distracter & Sentence \\
\hline For I & Example: The girl with the ribbon carries the ball. \\
\hline (i) incorrect lexical modifier & The girl with the glasses carries the ball. \\
\hline (ii) lexically incorrect direct object & The girl with the ribbon carries the basket. \\
\hline (iii) combination of (i) and (ii) & The girl with the glasses carries the basket. \\
\hline For II-V & Example: The man with the ball is looking for the child. \\
\hline (i) incorrect assignment of attribute & The man is looking for the child with the ball. \\
\hline (ii) reversed agent-patient role & The child is looking for the man with the ball. \\
\hline (iii) combination of (i) and (ii) & The child with the ball is looking for the man. \\
\hline
\end{tabular}

of incorrect and correct companion sentences were assigned to the different lists. Each list of 120 sentences was divided into three blocks of 40 sentences. A pseudorandomized sequence of sentences was used for each list. The sequence was such that in immediate succession no more than two incorrect sentences from the same violation type occurred. Incorrect and correct sentences never occurred more than three times in a row. Each list was presented to all subjects in two different sessions separated by at least 4 weeks. The presentation order of the two lists was counterbalanced. The experimental list was preceded by a practice list of 20 items to familiarize the subjects with the experimental situation and to train them to fixate their eyes during sentence presentation and to blink only between trials. In order to induce the subjects to listen attentively to the sentences, a questionnaire was constructed with four questions per block about the content of a sentence.

A pulse for triggering the EEG acquisition program was placed 150 msec before onset of each experimental sentence. Each $8 \mathrm{sec}$ a sentence was presented. Three tapes were constructed: a practice tape containing 20 practice items and two tapes for the two experimental lists.

In addition to the test tapes with the sentence stimuli, a digital audiotape was constructed with tones. This tape contained 300 tones, 60 tones of $1 \mathrm{kHz}$ and 240 tones of $2 \mathrm{kHz}$. The tones were presented in a random order with 20-msec duration and a frequency of one per second. A trigger pulse was placed before the onset of each $1-\mathrm{kHz}$ tone, and before the onset of 60 randomly chosen $2 \mathrm{kHz}$ tones. The experimental tones were preceded by 50 practice tones in order to familiarize the subjects with the stimuli and the task.

\section{Procedure}

Subjects were tested individually in a dimly illuminated sound-attenuating booth. They were instructed to keep their eyes fixated on a point at eye level. Subjects were told that they would hear sentences, some of which had language errors in them, but they were given no information concerning the kind of errors that would occur. Subjects were asked to listen attentively to the sentences. They were told that the experimenter would sometimes stop the tape to ask them a question about a sentence they had just heard. No additional task demands were imposed. All stimuli were presented via a DAT recorder. Subjects listened to the stimuli via closedear headphones. 


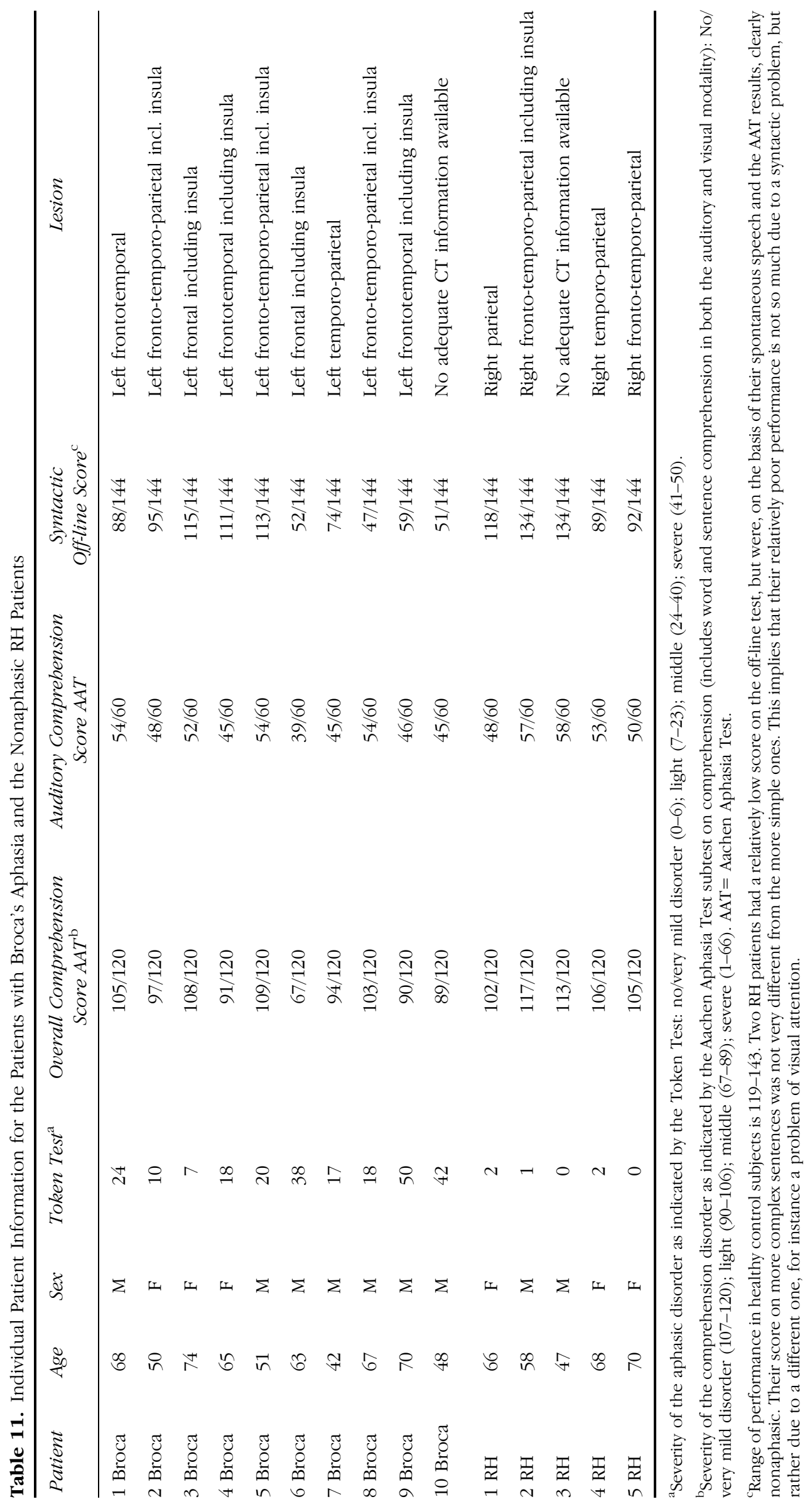


The ERPs to the tones in the oddball paradigm were recorded in a separate session. Subjects were asked to silently count the low tones, and to give a running total at the end of the session. The practice session of the tone oddball task was used to establish whether patients were able to silently count the low tones. Three patients were unable to count. For these subjects it was established that they could discriminate between the 1- and $2-\mathrm{kHz}$ tones (by raising a hand upon the occurrence of a low tone) and they were instructed to listen attentively, without an additional task.

\section{EEG Recording}

EEG activity was recorded by using an Electrocap (Eaton, $\mathrm{OH})$ with 13 scalp tin electrodes, each referred to the left mastoid. Nine electrodes (Fz, Cz, Pz, F7, F8, FT7, FT8, $\mathrm{PO} 7, \mathrm{PO} 8)$ were placed according to the standards of the American Electroencephalographic Society. Four electrodes were placed over nonstandard intermediate locations: temporal pair (LT and RT) placed 33\% of the interaural distance lateral to $\mathrm{Cz}$, and a temporo-parietal pair (LTP and RTP) placed 30\% of the interaural distance lateral to $\mathrm{Cz}$ and $13 \%$ of the inion-nasion distance posterior to $\mathrm{Cz}$ ). The ERPs to the tones in the oddball paradigm were recorded with a subset of these 13 electrodes, viz., Fz, Cz, Pz, FT7, FT8, LTP and RTP (seven electrodes). Vertical eye movements and blinks were monitored via a supra- to suborbital bipolar montage. A right to left canthal bipolar montage was used to monitor for horizontal eye movements. Activity over the right mastoid

Table 12. Example of the Stimulus Materials Belonging to the Conjoined (1a and $1 \mathrm{~b}$ ) and the Embedded (2a and $2 \mathrm{~b}$ ) Condition (Critical Words in Italics)

Relatively simple constituent structure (conjoined) ${ }^{\mathrm{a}}$

(1a) De vrouwen betalen de bakker en nemen het brood mee naar huis. (The women pay the baker and take the bread home.)

(1b)* De vrouwen betalen de bakker en neemt het brood mee naar huis. (The women pay the baker and takes the bread home.)

\section{Relatively complex constituent structure (embedded) ${ }^{\mathrm{b}}$}

(2a) De vrouwen die de bakker betalen, nemen het brood mee naar huis. (The women who pay the baker, take the bread home.)

(2b)* De vrouwen die de bakker betalen, neemt het brood mee naar huis. (The women who pay the baker, takes the bread home.)

*Violations

${ }^{a}$ Conjoined: the two verb phrases are expressed by a conjunction.

${ }^{b}$ Embedded: one of the verb phrases is embedded in the subject noun phrase.

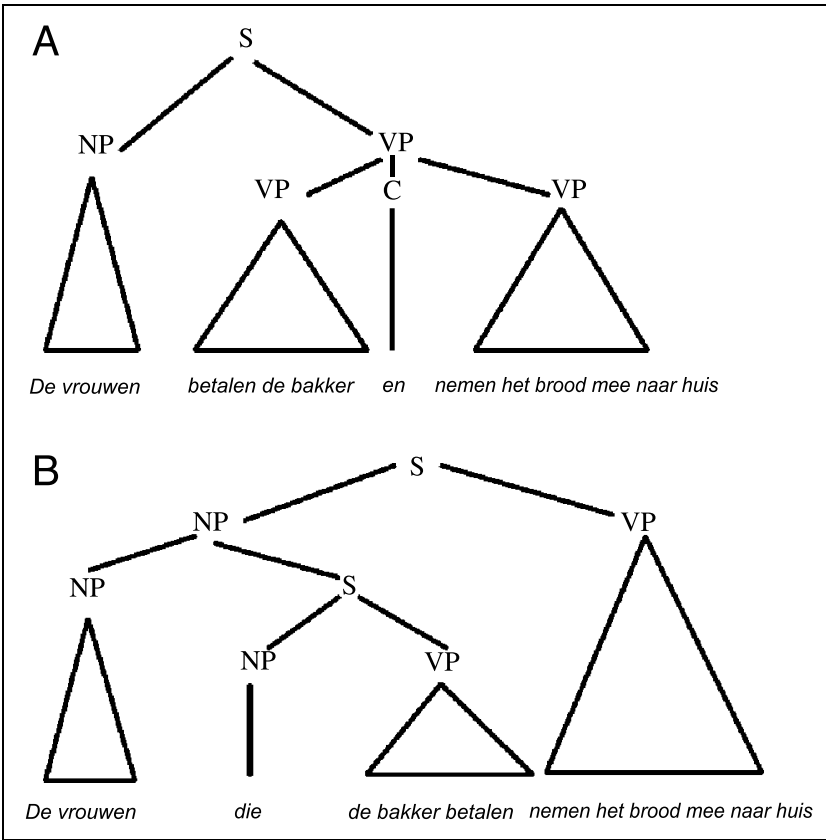

Figure 12. Syntactic trees for (A) a conjoined and (B) an embedded sentence. Note the additional $\mathrm{S}$ node for the embedded sentence. This extra level makes the embedded sentence syntactically more complex than the conjoined sentence. $\mathrm{S}=$ sentence; $\mathrm{NP}=$ noun phrase; VP $=$ verb phrase; $\mathrm{C}=$ conjunction. Translation conjoined sentence: The women pay the baker and take the bread home; translation embedded sentence: The women who pay the baker, take the bread home.

bone was recorded on an additional channel to determine whether experimental variables had any effect on the mastoid recordings. No such effects were observed. The ground electrode was placed on the forehead.

The EEG and EOG recordings were amplified with Nihon Kohden (Tokyo, Japan) AB-601G bioelectric amplifiers, using a Hi-Cut of $30 \mathrm{~Hz}$ and a time constant of 8 sec. Impedances were kept below $5 \mathrm{k} \Omega$. The EEG and EOG were digitized on-line with a sampling frequency of $200 \mathrm{~Hz}$. A trigger pulse started sampling $150 \mathrm{msec}$ before the presentation of the sentences and tones. The total sampling epoch for the sentence stimuli was $6315 \mathrm{msec}$ (150-msec presentence baseline + duration of longest sentence $+1000 \mathrm{msec}$ ). For the tone stimuli the total sampling epoch was $850 \mathrm{msec}$. Data were stored along with condition codes for subsequent off-line averaging and data analysis.

\section{Acknowledgments}

We thank A. Nevejan and C. Blaauw for their help in screening the neurological patients, M. ter Keurs for making available the CT scans, and E. Sjoerdsma for lending her voice to the stimuli. This research was supported in part by grant 400-56-384 from the Netherlands Organization for Scientific Research.

Reprint requests should be sent to M. Wassenaar or P. Hagoort, F. C. Donders Centre for Cognitive Neuroimaging, Adelbertusplein 1, P.O. Box 9101, NL-6500 HB Nijmegen, the Netherlands, 
or via e-mail: marlies.wassenaar@fcdonders.kun.nl or peter. hagoort@fcdonders.kun.nl.

\section{REFERENCES}

Ainsworth-Darnell, K., Shulman, H., \& Boland, J. (1998). Dissociating brain responses to syntactic and semantic anomalies: Evidence from event-related potentials. Journal of Memory and Language, 38, 112-130.

Caplan, D., Hildebrandt, N., \& Makris, N. (1996). Location of lesions in stroke patients with deficits in syntactic processing in sentence comprehension. Brain, 119, 933-949.

Coulson, S., King, J. W., \& Kutas, M. (1998a). ERPs and domain specificity: Beating a straw horse. Language and Cognitive Processes, 13, 653-672.

Coulson, S., King, J. W., \& Kutas, M. (1998b). Expect the unexpected: Event-related brain response to morphosyntactic violations. Language and Cognitive Processes, 13, 21-58.

Donchin, E. (1981). Surprise! ... Surprise? Psychophysiology, $18,493-513$.

Frazier, L. (1985). Syntactic complexity. In D. R. Dowty, L. Kartunnen \& A. M. Zwickley (Eds.), Natural language parsing. Cambridge: Cambridge University Press.

Friederici, A. D. (1988). Agrammatic comprehension: Picture of a computational mismatch. Aphasiology, 2, 279-282.

Friederici, A. D. (2001). Event-related brain potentials and aphasia. In R. S. Berndt (Ed.), Handbook of neuropsychology (Vol. 3, pp. 353-373). Amsterdam: Elsevier.

Friederici, A. D., Hahne, A., \& Mecklinger, A. (1996). Temporal structure of syntactic parsing: Early and late event-related brain potential effects. Journal of Experimental Psychology: Learning, Memory, and Cognition, 22, 1219-1248.

Friederici, A. D., \& Kilborn, K. (1989). Temporal constraints on language processing: Syntactic priming in Broca's aphasia. Journal of Cognitive Neuroscience, 1, 262-272.

Friederici, A. D., Pfeifer, E., \& Hahne, A. (1993). Event-related brain potentials during natural speech processing: Effects of semantic, morphological and syntactic violations. Cognitive Brain Research, 1, 183-192.

Graetz, P., De Bleser, R., \& Willmes, K. (1992). De Akense Afasie Test. Lisse: Swets \& Zeitlinger.

Gratton, G., Coles, M. G. H., \& Donchin, E. (1983). A new method for off-line removal of ocular artifact. Electroencephalography and Clinical Neurophysiology, 55, 468-484.

Gunter, T. C., Stowe, L. A., \& Mulder, G. M. (1997). When syntax meets semantics. Psychophysiology, 34, 660-676.

Haarmann, H. J., Just, M. A., \& Carpenter, P. A. (1997). Aphasic sentence comprehension as a resource deficit: A computational approach. Brain and Language, 59, 76-120.

Haarmann, H. J., \& Kolk, H. H. J. (1991a). A computer model of the temporal course of agrammatic sentence understanding: The effects of variation in severity and sentence complexity. Cognitive Science, 15, 49-87.

Haarmann, H. J., \& Kolk, H. H. J. (1991b). Syntactic priming in Broca's aphasics: Evidence for slow activation. Aphasiology, 5, 247-263.

Haarmann, H. J., \& Kolk, H. H. J. (1994). On-line sensitivity to subject-verb agreement violations in Broca's aphasia: The role of syntactic complexity and time. Brain and Language, 46, 493-516.

Hagoort, P. (1990). Tracking the time course of language understanding in aphasia. Unpublished doctoral dissertation, University of Nijmegen, Netherlands.
Hagoort, P. (1993). Impairments of lexical-semantic processing in aphasia: Evidence from the processing of lexical ambiguities. Brain and Language, 45, 189-232.

Hagoort, P., \& Brown, C. M. (2000). ERP effects of listening to speech compared to reading: The P600/SPS to syntactic violations in spoken sentences and rapid serial visual presentation. Neuropsychologia, 38, 1531-1549.

Hagoort, P., Brown, C. M., \& Groothusen, J. (1993). The syntactic positive shift (SPS) as an ERP measure of syntactic processing. Language and Cognitive Processes, 8 , 439-483.

Hagoort, P., Brown, C. M., \& Osterhout, L. (1999). The neurocognition of syntactic processing. In C. M. Brown \& P. Hagoort (Eds.), The neurocognition of language (pp. 273-316). Oxford, UK: Oxford University Press.

Hagoort, P., Brown, C. M., \& Swaab, T. Y. (1996). Lexical-semantic event-related potential effects in patients with left hemisphere aphasia and patients with right hemisphere lesions without aphasia. Brain, 119, 627-649.

Hagoort, P., Wassenaar, M., \& Brown, C. M. (2003). Real-time semantic compensation in patients with agrammatic comprehension: Electrophysiological evidence for multiple-route plasticity. Proceedings of the National Academy of Sciences, U.S.A., 100, 4340-4345.

Huber, W., Klingenberg, G., Poeck, K., \& Willmes, K. (1993). Die Supplemente zum Aachener Aphasic Test: Aufbau und Resultate der Validierung. Neurolinguistik, 7, 43-66.

Indefrey, P. (2001). A meta-analysis of PET and fMRI experiments on syntactic parsing. Neuroimage, 13, 545.

Kaan, E., Harris, A., Gibson, E., \& Holcomb, P. (2000). The P600 as an index of syntactic integration difficulty. Language and Cognitive Processes, 15, 159-201.

Kluender, R., \& Kutas, M. (1993). Subjacency as a processing phenomenon. Language and Cognitive Processes, 8, 573-633.

Kolk, H. H. J. (1998). Disorders of syntax in aphasia: Linguistic-descriptive and processing approaches. In B. Stemmer \& H. A. Whitaker (Eds.), Handbook of neurolinguistics (pp. 250-261). San Diego: Academic Press.

Kutas, M., \& Hillyard, S. A. (1980). Reading senseless sentences: Brain potentials reflect semantic anomaly. Science, 207, 203-205.

Miyake, A., Carpenter, P. A., \& Just, M. A. (1994). A capacity approach to syntactic comprehension disorders: Making normal adults perform like aphasic patients. Cognitive Neuropsychology, 11, 671-717.

Miyake, A., Carpenter, P. A., \& Just, M. A. (1995). Reduced resources and specific impairments in normal and aphasic sentence comprehension. Cognitive Neuropsychology, 12, 651-679.

Münte, T. F., \& Heinze, H. J. (1994). ERP negativities during syntactic processing of written words. In H. J. Heinze, T. F. Münte, \& G. R. Mangun (Eds.), Cognitive electrophysiology. Boston, MA: Birkhauser.

Münte, T. F., Heinze, H. J., \& Mangun, G. R. (1993). Dissociation of brain activity related to syntactic and semantic aspects of language. Journal of Cognitive Neuroscience, 5, 335-344.

Münte, T. F., Matzke, M., \& Johannes, S. (1997). Brain activity associated with syntactic incongruities in words and pseudo-words. Journal of Cognitive Neuroscience, 9, 300-311.

Neville, H., Nicol, J. L., Barss, A., Forster, K. I., \& Garrett, M. F. (1991). Syntactically based sentence processing classes: Evidence from event-related brain potentials. Journal of Cognitive Neuroscience, 3, 151-165.

Nicol, J. L., Forster, K. I., \& Veres, C. (1997). Subject-verb 
agreement processes in comprehension. Journal of Memory and Language, 36, 569-587.

Oldfield, R. C. (1971). The assessment and analysis of handedness: The Edinburgh inventory. Neuropsychologia, 9, 97-113.

Osterhout, L., \& Hagoort, P. (1999). A superficial resemblance does not necessarily mean you are part of the family: Counterarguments to Coulson, King and Kutas (1998) in the P600/SPS-P300 debate. Language and Cognitive Processes, 14, 1-14.

Osterhout, L., \& Holcomb, P. J. (1992). Event-related brain potentials elicited by syntactic anomaly. Journal of Memory and Language, 31, 785-806.

Osterhout, L., \& Holcomb, P. J. (1993). Event-related potentials and syntactic anomaly: Evidence of anomaly detection during the perception of continuous speech. Language and Cognitive Processes, 8, 413-438.

Osterhout, L., Holcomb, P. J., \& Swinney, D. A. (1994). Brain potentials elicited by garden-path sentences: Evidence of the application of verb information during parsing. Journal of Experimental Psychology: Learning, Memory, and Cognition, 20, 786-803.

Osterhout, L., McKinnon, R., Bersick, M., \& Corey, V. (1996). On the language-specificity of the brain response to syntactic anomalies: Is the syntactic positive shift a member of the P300 family? Journal of Cognitive Neuroscience, 8, 507-526.

Osterhout, L., \& Mobley, L. A. (1995). Event-related brain potentials elicited by failure to agree. Journal of Memory and Language, 34, 739-773.

Rösler, F., Friederici, A. D., Pütz, P., \& Hahne, A. (1993). Event-related brain potentials while encountering semantic and syntactic constraint violations. Journal of Cognitive Neuroscience, 5, 345-362.

Saffran, E. M., Dell, G. S., \& Schwartz, M. F. (2000). Computational modeling of language disorders. In M. S. Gazzaniga (Ed.), The new cognitive neurosciences (2nd ed., pp. 933-948). Cambridge: MIT Press.

Swaab, T. Y., Brown, C. M., \& Hagoort, P. (1997). Spoken sentence comprehension in aphasia: Event-related potential evidence for a lexical integration deficit. Journal of Cognitive Neuroscience, 9, 39-66.

Ter Keurs, M., Brown, C. M., Hagoort, P., \& Stegeman, D. F. (1999). Electrophysiological manifestations of open- and closed-class words in patients with Broca's aphasia with agrammatic comprehension: An event-related brain potential study. Brain, 122, 839-854.

Van Berkum, J. J. A., Brown, C. M., \& Hagoort, P. (1999). Early referential context effects in sentence processing: Evidence from event-related brain potentials. Journal of Memory and Language, 41, 147-182.

Vosse, T., \& Kempen, G. (2000). Syntactic structure assembly in human parsing: A computational model based on competitive inhibition and a lexicalist grammar. Cognition, 75, 105-143. 